\title{
La responsabilidad civil extracontractual por el daño ambiental causado en la construcción u operación de las carreteras*
}

\author{
Verónica Delgado Schneider**
}

\begin{abstract}
RESUMEN
Se pretende determinar en Chile cuándo hay daño "significativo" al medio ambiente y cuál es el régimen de responsabilidad civil extracontractual para exigir su reparación material, cuando éste se ha causado con ocasión de la construcción y operación de una carretera, con especial atención a si ella es concesionada, precisando las características más importantes de la normativa (y su futura reforma con la ley de tribunales ambientales) y revisando la jurisprudencia existente. Se concluye que el estándar de conducta impuesto a las concesionarias, por la ley (de concesiones y ambiental) y nuestros tribunales, es extremadamente exigente en materia de culpa; que no resulta adecuada la restringida legitimación activa en la acción ambiental, especialmente cuando el causante del daño es el propio Estado; y que, frente a daños irreparables, más que una indemnización convendría compensar in natura.
\end{abstract}

Daño ambiental - concesiones de obras públicas - daño significativo

\section{Non-contractual civil liability for environmental damage caused in road construction or operation}

\begin{abstract}
This paper intends to determine when there is "significant" damage to the environment and which is the tort system to demand material repair, when it has been caused on the occasion of the construction and operation of roads, with special attention to whether it is a concession, pointing out the most relevant features of the legislation (and its future reform with the Environmental Courts Act) and reviewing the existing case law. It is concluded that the standard of conduct imposed to concessionaires by law (Concession Act and Environmental legislation) and our courts, is extremely demanding in terms of guilt; that the restricted locus standi in the environmental action, especially when the damage has been caused by the State itself; and that, facing irreparable damage, rather than a monetary compensation, a in natura compensation should be more advisable.
\end{abstract}

Environmental damage - public works concessions - significant damage

* Este trabajo es producto del proyecto Fondecyt regular $\mathrm{N}^{\circ} 1100949$, denominado "Responsabilidad civil de las concesionarias de autopistas por daños causados a usuarios y al medio ambiente con motivo de la ejecución o explotación de la obra: análisis crítico de su funcionamiento y propuestas de racionalización", del cual la autora es coinvestigadora.

** Abogada, Doctora en derecho, Profesora de Derecho Ambiental y Económico, Facultad de Ciencias Jurídicas y Sociales, Universidad de Concepción, Chile. vdelgadosch@gmail.com

Artículo recibido el 30 de marzo de 2012 y aceptado para su publicación por el Comité Editorial el 31 de mayo de 2012. 


\section{INTRODUCCIÓN}

En relación a las obras viales, los mayores impactos o daños al medio ambiente se generan o empiezan a generarse en la etapa de construcción de las obras, pudiendo agravarse durante la operación, hacerse permanentes o generarse nuevos. En general, aludimos a pérdida de suelo y erosión, corta de vegetación, afectación de los hábitats naturales de la fauna del lugar, eventuales contaminaciones al agua y suelo, transformación del paisaje etc.; y en la ciudad, deterioro a la calidad de vida de las personas por ruido y polvo, entre otros muchos impactos ${ }^{1}$.

Estos impactos, menores o mayores, estarán justificados en nuestra legislación si el proyecto se somete a una evaluación ambiental previa ante la institucionalidad ambiental y cumple su obligación de mitigar, reparar o compensar apropiadamente los efectos adversos significativos que generará cuando ejecute el proyecto, como condición para obtener y mantener sus autorizaciones o permisos ambientales.

Sin embargo, en la práctica, puede darse el caso de daños ambientales causados al margen de estas autorizaciones, o por no seguir las prescripciones condicionales de ellas (por ejemplo, no reparando apropiadamente), o porque no fueron previstos en la evaluación del proyecto ni por el titular ni por el Estado evaluador y, en consecuencia, nada se exigió reparar.

Nuestros objetivos son determinar en Chile cuándo hay daño ambiental y cuál es el régimen legal aplicable a la acción de responsabilidad civil extracontractual que exigirá la reparación de ese daño, cuando éste se ha causado con ocasión de la construcción y operación de una carretera, con especial atención a si ella está sometida al régimen de concesión (pues la mayoría de ellas lo está), precisando las características más importantes de esta normativa y revisando la jurisprudencia aún escasa existente.

Sin embargo, antes haremos una breve alusión a la utilización de este instrumento de derecho privado en materia ambiental considerando el derecho y doctrina extranjera.

\section{LA RESPONSABILIDAD CIVIL EXTRACONTRACTUAL POR DAÑO AMBIENTAL}

Si bien la protección del medio ambiente corresponde fundamentalmente al Estado -a través del derecho administrativo y penal, en una fase preventiva y/o represiva-, hace ya 20 años aproximadamente la responsabilidad civil extracontractual por daño ambiental está jugando un rol complementario a esta labor pública ${ }^{2}$.

${ }^{1}$ Para los impactos, ver V. Sancho Gómez, Fuencisla, "Sostenibilidad ambiental en la fase de explotación de las autopistas de peaje de titularidad estatal”, en Revista de Obras Públicas (España), N 3524, sept. 2011, p. 7 ss. y específicamente para los impactos en el país de las autopistas urbanas, v. Greene, M.-Mora, R., "Las autopistas urbanas concesionadas. Una nueva forma de segregación”, en Revista ARQ Ensayos y Documentos $\mathrm{N}^{\circ} 60$, junio 2005, pp. 56-58, y Brahm, A. “Autopistas urbanas”, en Revista ARQ Ensayos y Documentos N 60, junio 2005, pp. 28-39.

${ }^{2}$ Con aprensiones, en un excelente estudio nacional y comparado, Banfi, C., "De la responsabilidad civil como instrumento de protección ambiental" en Revista Chilena de Derecho Privado, Fundación Fernando Fueyo L.-Universidad Diego Portales, N², 2004, pp. 19-70. 
Lo importante -como destaca la doctrina especializada ${ }^{3}$ - es tener claro que el daño que se busca reparar no es el que sufren los particulares en su patrimonio, vida o salud, con ocasión de un daño ambiental, sino reparar el daño ambiental "puro”, "público” o "colectivo". Si se contamina un río, la acción civil por daño ambiental busca su descontaminación, por ejemplo, dragándolo para sacar los metales pesados depositados en su fondo, y no la reparación económica por los daños causados al dueño de los vacunos que murieron por envenenamiento, o los niños que se intoxicaron al beber agua captada de ese río, o el camping que no recibió más clientes, etc. En este último caso, se señala que estos "daños reflejos" se han podido demandar siempre, como daño emergente, lucro cesante o daño moral, en base al derecho común (en Chile, arts. 2314 y siguientes del Código Civil).

El daño personal o reflejo es el daño ambiental "en su perspectiva humana", es decir, es el perjuicio personal o patrimonial sufrido por la vía del ataque al medio ambiente.

El daño ambiental puro o strictu sensu es aquel causado al medio ambiente o a uno de sus elementos como realidad autónoma de los valores ortodoxos asociados a la salud y al patrimonio ${ }^{4}$. Su titular es la comunidad toda y cada uno de sus miembros. Se trata de un daño a un bien de todos, por ende, "público" o "colectivo"

Una vez que se tuvo clara la distinción entre ambos daños -que no siempre es fácil, pues integran el ambiente bienes privados y públicos ${ }^{6}$ y luego de que en la Declaración

\footnotetext{
${ }^{3}$ Benjamin, A. "A responsabilidade civil pelo dano ambiental no direito brasileiro e as lições do direito comparado", en Revista Roma e America, Diritto romano comune, Universidad de Roma - Tor Vergata, N 6, 1998, pp. 129-130, citando al francés M. Prieur quien en 1984 planteó por primera vez el tema de la "autonomía" del daño ambiental puro del reflejo.

${ }^{4}$ V. Camps, C., "Particularidades del proceso civil por daño ambiental", en Jurisprudencia Ambiental (Arg.) IV, 1998, p. 31 ss, citando a Bustamante Alsina, Jorge: "Se ha recordado que 'daño ambiental' es una expresión ambivalente, pues designa no solamente el daño que recae en el patrimonio ambiental que es común a una comunidad, en cuyo caso hablamos de 'impacto ambiental', sino que se refiere también al daño que el medio ambiente ocasiona de rebote (par ricochet como dicen los franceses) a los intereses legítimos de una persona determinada, configurando un daño particular que ataca un derecho subjetivo y legitima al damnificado para accionar en reclamo de una reparación o resarcimiento del perjuicio patrimonial o extrapatrimonial que le ha causado”. Por su parte, Andorno, L., "Aspectos constitucionales de la protección al medio ambiente”, en Jurisprudencia Ambiental (Arg.), IV, 1998, p. 10, señala que "la actividad industrial origina dos tipos de daños: los que afectan a la salud e integridad psicofísica del hombre, y los que limitan el derecho de gozar de un medio ambiente salubre”.

${ }^{5}$ Busnelli, F., Illecito civile (estratto dall'aggiornamento I della Enciclopedia Giuridica 1991), Istituto della Enciclopedia Italiana, Roma, 1991, p. 15. Se refiere a una "peculiar dimensión del daño colectivo”, que define como un daño público; Andorno, L., "Aspectos constitucionales de la protección al medio ambiente”, cit., p. 9, también lo define como un daño "colectivo".

${ }^{6}$ De hecho, en Chile se han acogido demandas interpuestas por el Consejo de Defensa del Estado en contra de particulares por causar daños ambientales en sus propiedades y respecto de sus bienes privados. El caso más emblemático es el fallo del 2010 que impone a un privado la obligación de reparar el daño ambiental causado por la corta de 25 de sus alerces. La sentencia señala: "Que tal como se razonó en el fallo de casación, el Estado de Chile reviste la calidad de "directamente afectado" atendida la especial situación jurídica de la especie vegetal sobre la cual recayó el daño, ya que por haberse declarado el alerce como Monumento Natural con las consecuencias que ello implica, tanto su tala como su explotación se encuentran prohibidas. Asimismo, por tratarse de un perjuicio de carácter permanente que no admite reparación y que constituye una disminución en la biodiversidad que conforma el patrimonio ambiental de la Nación, el Estado de Chile se encuentra legitimado en este caso
} 
de Río sobre el Medio Ambiente y Desarrollo de 1992 más de 160 Estados suscribieran el principio de la responsabilidad ${ }^{7}$ (y otros agregan el principio quien contamina, paga $^{8}$ ) hubo un rápido proceso en América Latina en que, incluso a nivel constitucional, se reconoció la "autonomía” del daño ambiental puro consagrando la obligación de repararlo, junto a las demás sanciones administrativas y penales que procedan y sin perjuicio de las indemnizaciones que correspondan a los personalmente afectados 9 . Reconocida la autonomía del daño ambiental se da el primer paso para su reparación a través del mecanismo de la responsabilidad civil extracontractual.

Sin embargo, la experiencia también ha demostrado que para lograr una protección efectiva, este mero reconocimiento de la obligación de reparar el daño ambiental "puro" no es suficiente y que es necesario acompañarlo de una serie de normas especiales que atiendan a sus particulares características, como una legitimación activa amplia, responsabilidad objetiva, solidaridad, norma especial en materia de prescripción, obligación de reparar prioritariamente in natura; seguros obligatorios ${ }^{10}$, para las actividades riesgosas o que pueden generalmente causar daños caros de reparar. Además, dado su carácter técnico, se recomienda contar con tribunales especializados, apreciar la prueba de acuerdo a las reglas de la sana crítica o sistemas flexibles semejantes y considerar definiciones legales de daño ambiental o ambiente, para ayudar a los jueces a enmarcar la protección, teniendo presente que lo que quede fuera de ellas, en consecuencia, deberá ser reparado por otras vías.

En Chile, la Ley N 19.300, Ley de Bases Generales del Medio Ambiente (en adelante, LBGMA) regula la materia en los arts. 51 y ss., bajo el título III De la responsabilidad

particular para demandar la indemnización que solicita (considerando 5)". V. Sentencia C.S., 31.08.2010, “Fisco de Chile con Soc. Forestal Candelaria de Río Puelo S. A. y otros", Rol n 5027-2008 (cons. $5^{\circ}$ ).

7 "PRINCIPIO 13: Los Estados deberán desarrollar la legislación nacional relativa a la responsabilidad y la indemnización respecto de las víctimas de la contaminación y otros daños ambientales. Los Estados deberán cooperar asimismo de manera expedita y más decidida en la elaboración de nuevas leyes internacionales sobre responsabilidad e indemnización por los efectos adversos de los daños ambientales causados por las actividades realizadas dentro de su jurisdicción, o bajo su control, en zonas situadas fuera de su jurisdicción”. En Declaración de Río sobre el Medio Ambiente y Desarrollo de 1992, Naciones Unidas, 1992, disponible en: http://www.un.org/ esa/dsd/agenda21_spanish/res_riodecl.shtml.

8 "PRINCIPIO 16: "Las autoridades nacionales deberían procurar fomentar la internalización de los costos ambientales y el uso de instrumentos económicos, teniendo en cuenta el criterio de que el que contamina debe, en PRINCIPIO, cargar con los costos de la contaminación, teniendo debidamente en cuenta el interés público y sin distorsionar el comercio ni las inversiones internacionales". En Declaración de Río sobre el Medio Ambiente y Desarrollo de 1992, Naciones Unidas, 1992, disponible en: http://www.un.org/esa/dsd/agenda21_spanish/ res_riodecl.shtml.

${ }^{9}$ Argentina consagra la obligación de reparar el daño ambiental en el art. 41 de la Constitución Nacional; Brasil en el art. $225 \mathrm{n}^{\text {os }} 2$ y 3 de la Constitución y lo reitera en los arts. 4 inc. VII y 14 de la Ley 6938 de Política Nacional del Medio Ambiente; Paraguay en el art. 8 de su Constitución; y en Uruguay se deduce del art. 47 de la Constitución y se explicita en el art. 4 de la Ley 16.466 de Evaluación de Impacto Ambiental. Bolivia consagra esta obligación en el art. 102 de la Ley 1333, General del Ambiente al consagrar la acción civil ambiental y con más claridad en el art. 108 del Reglamento de Gestión Ambiental y Chile en los arts. 3 y 51 inc. 1 de la LBGMA.

${ }^{10}$ Para una primera aproximación al tema, Amunátegui, A., "Responsabilidad civil ambiental y seguro", en Revista de Derecho de la Empresa, Universidad Adolfo Ibáñez - Legis, n 6, 2006, pp. 25-40. 
por daño ambiental, modificado en enero del año 2010, por la Ley $\mathrm{N}^{\circ} 20.417$ y que deberá complementarse con las nuevas normas contenidas en el proyecto de ley que crea los Tribunales Ambientales, de pronta vigencia, dado que el pasado 27 de febrero pasó al examen del Tribunal Constitucional.

Revisaremos este nuevo régimen ${ }^{11}$, con especial atención a los daños ambientales asociados a nuestra infraestructura vial.

\section{3. ¿CUÁNDO HAY DAÑO AMBIENTAL?}

La LBGMA define al daño ambiental, para todos los efectos legales, como "toda pérdida, disminución, detrimento o menoscabo significativo inferido al medio ambiente o a uno o más de sus componentes (art. 2 letra e)”. Se redacta con los mismos sustantivos, "ahora atribuidos al ambiente", utilizados en la definición de daño más conocida en la doctrina chilena" 12 . Por otra parte, se define al medio ambiente como "el sistema global constituido por elementos naturales y artificiales de naturaleza física, química o biológica, socioculturales y sus interacciones, en permanente modificación por la acción humana o natural y que rige y condiciona la existencia y desarrollo de la vida en sus múltiples manifestaciones" (art. 2 letra ll).

La conjunción de las definiciones de daño ambiental y medio ambiente permite afirmar que la cobertura que se da para exigir la reparación del daño ambiental "puro" es amplísima. En primer lugar, pues no sólo es daño ambiental la afectación inferida a uno o más componentes naturales del medio ambiente, sino a cualquiera de sus componentes artificiales, incluidos los socioculturales. De hecho, ya existen varias condenas de daños a este tipo de componentes ${ }^{13}$ y pudieran darse perfectamente en el área que

${ }^{11}$ Para una visión general del régimen de responsabilidad civil extracontractual por daño ambiental en Chile (antes de la reforma de la ley 20.417) ver: Corral, H., "Daño ambiental y responsabilidad civil del empresario en la ley de bases del medio ambiente”, en Revista Chilena de Derecho, P. Universidad Católica de Chile, vol. 23 No 1, 1996, pp. 143-177; Valenzuela, R., "Responsabilidad civil por daño ambiental en la legislación chilena", en Roma e America, Diritto romano comune, Universidad de Roma - Tor Vergata, No 11, 2001, pp. 3-19; Fernández, P., "Responsabilidad y acción ambiental”, en Ius Publicum, Universidad Santo Tomás, N 10, 2003, pp. 89-96, Barros, E., Tratado de responsabilidad extracontractual, 1a edición, Editorial Jurídica de Chile, Santiago, 2006, 1230 p., y Valenzuela R., Derecho ambiental: presente y pasado, Edit. Jurídica de Chile, Santiago, 2010, 448 p.

12 Corral, H., "Daño ambiental y responsabilidad civil del empresario en la ley de bases del medio ambiente", cit., 164 y 165. La definición de Arturo Alessandri en efecto decía: "hay daño cada vez que un individuo sufre una pérdida, disminución, detrimento o menoscabo en su persona o bienes o en las ventajas o beneficios patrimoniales o extrapatrimoniales de que gozaba".

${ }^{13}$ Como cuando se acogieron acciones por daño ambiental por la instalación de antenas de telecomunicaciones en una zona declarada típica (Sentencia J.L. Civ. La Serena, 7.12.2001, "Fisco de Chile con Empresa C.T.C. Startel S.A.”, Rol 306-2000; confirmada por C. Ap. La Serena, 17.10.2002, Rol n 26.636; C.S., 30.12.2003 rechaza casación, Rol n 4.864-2002); por la demolición de un monumento histórico como la casa de Huéspedes de Antofagasta (Sentencia C. Ap. Antofagasta, 19.04.2004, "Fisco de Chile con Sociedad Química y Minera de Chile" que revoca la de 1er grado, Rol n 16.391, y sentencia C.S., 30.08.2006, "Fisco de Chile con Sociedad Química y Minera de Chile" que acoge casación, confirmando la de 1er grado, Rol n 1.911-2004, Id. Legal publishing $\mathrm{n}^{\circ}$ 35145, comentada en V. Poklepovic Meersohn, I., "Aspectos vinculados a la protección del patrimonio cultural 
estudiamos, dada la gran cantidad de proyectos que se ejecutan en o próximos a áreas protegidas oficialmente como patrimonio cultural $^{14}$.

En segundo lugar, a diferencia de lo que ocurre con el recurso de protección ${ }^{15}$, la tutela no está solo circunscrita a lesiones al medio ambiente que afecten la vida del hombre ${ }^{16}$, sino que la ley es clara en señalar que se trata de un sistema que rige y condiciona la existencia de la vida, pero en sus múltiples manifestaciones, como cuando se daña a la flora, fauna, ambientes no habitados (como construir una carretera en la Patagonia) etc., casos que, por no importar "contaminación" a "personas", no han encontrado protección en la sede constitucional, ni siquiera en su fase de amenaza ${ }^{17}$.

a través del ejercicio de la acción ambiental de la ley $\mathrm{N}^{\circ} 19.300$ sobre bases del medio ambiente", en Revista de Derecho, Consejo de Defensa del Estado, vol. 16, N 16, diciembre 2006, pp. 185-198, y por la destrucción de patrimonio arqueológico (un conchal) en Bahía Ilque, en Puerto Montt (Sentencia de primera instancia y C. Ap. Pto. Montt, 17.01.2007, "Fisco de Chile con Cía. Industrial Pto. Montt S.A.", Rol n 638-2006); comentadas en Ropert Fuentes, R., y Saavedra Fernández, R., "La protección del patrimonio cultural en la ley 19.300 de bases generales de medio ambiente a la luz de dos sentencias recientes", en Revista de Derecho, Consejo de Defensa del Estado, vol. 11, N 11, junio 2004, pp. 191-221; y en Uriarte Rodríguez, A., "Jurisprudencia ambiental", en Revista de Derecho, Consejo de Defensa del Estado, vol. 16, N 16, diciembre 2006, pp. 99-146.

${ }^{14}$ Por ejemplo, en el proyecto Alternativo Costanera Norte, que contemplaba obras en la Zona Típica Parque Forestal, en la evaluación ambiental, el titular se compromete, a fin de evitar daños, a mantener permanentemente un arqueólogo para supervisar, paralizar las faenas y denunciar al Consejo de Monumentos Nacionales el hallazgo de algún tajamar, realizar un levantamiento, registro y numeración in situ del material a extraer de los tajamares y además a realizar en el lugar en que se ubicaron las cepas del Puente Cal y Canto una prospección arqueológica, mediante puentes de sondeo. (Según Resolución de Calificación Ambiental n 125/2002, 22.02.2002, de la (ex) Comisión Regional del Medio Ambiente de la Región Metropolitana).

${ }^{15}$ Para la protección constitucional del medio ambiente en general, recomiendo Guzmán Rosen, Rodrigo, $L a$ regulación constitucional del ambiente en Chile. Aspectos sustantivos y adjetivos, historia, doctrina y jurisprudencia, $2^{\mathrm{a}}$ edición, Abeledo Perrot, Santiago, 2010, 357 p.

${ }^{16}$ En contra, Corral, H., "Daño ambiental y responsabilidad civil del empresario en la ley de bases del medio ambiente", cit., pp. 168-169.

17 En efecto, la garantía constitucional establece que la Constitución asegura a todas las "personas" el derecho a "vivir" en un medio ambiente "libre de contaminación". Por ello y entre otras razones se rechazó, por ejemplo, el recurso destinado a parar la muerte de lobos de mar por la autoridad por afectar las redes de los pescadores. La Corte Suprema confirmó la sentencia de primera instancia que señalaba: "No obstante, lo analizado en los fundamentos anteriores, es del caso señalar que el recurso de protección ... está dirigido a proteger las garantías constitucionales de las personas y no alcanza su ámbito de protección a otros seres vivientes, lo que no hace imposible impetrar, a través de esta vía, una cautela sobre estos mamíferos marinos”. (considerando 10). El fallo de la Excma. Corte Suprema fue acordado, en todo caso, con el voto en contra del Ministro Sr. Jordán quien señaló: "En el asunto específico a que se refiere el recurso, la medida que pretende adoptar la Subsecretaría de Pesca, constituye, por su índole, una amenaza que implica arbitrariedad, pues compromete un medio ambiente libre de contaminación, con respecto a lo cual obviamente se debe tutelar la preservación de la naturaleza que constituye un todo, una unidad que involucra la creación misma con todos los seres, elementos y materias que la integran y que convergen al equilibrio ecológico, a la mantención del patrimonio ambiental, tanto más cuanto que los lobos marinos representan una especie protegida". Sentencia C.S., 25.02.1999, "Sociedad de amigos de los animales con Subsecretaría de Pesca", Recurso de protección, Rol 259-1999, N Legal Publishing: 15724.

Excepcionalmente, se han acogido recursos en el sentido más amplio. Por ejemplo, se acogió un recurso de protección ante la poda "mutilatoria" de los árboles de una avenida de Valdivia, pero fue calificado - por la Corte y no por el recurrente-como un caso de "contaminación visual” para las personas habitantes de la ciudad. Sentencia C. Apelaciones Valdivia, 21.12.2007, "Luis Felipe Fernández Larraguibel con 
Comentario aparte merece la expresión "significativo" que la LBGMA agregó a la definición de daño de Alessandri y que hoy también existe como requisito en la Unión Europea $^{18}$ y en la legislación nacional de muchos de sus Estados. Corresponde simplemente a "importante"19 (como señala el Diccionario de la RAE) y no necesariamente "grave”, como se ha pretendido ${ }^{20}$. Incluso más, podría simplemente querer aclarar que hay impactos ambientales o molestias a la calidad de vida que deben tolerarse pues son "normales" en la vida en sociedad que llevamos y que, por ende, la acción debe ejercerse respecto de alteraciones anormales. ${ }^{21}$ Esto puede ser muy importante en materia de carreteras, especialmente por el ruido que de noche y de día generan, muchas veces cerca de barrios residenciales y donde, al no existir norma aplicable para el ruido causado por fuentes móviles, será la autoridad ambiental la que fije el límite permitido, "normal" o "tolerable"; o en fin, los jueces de la causa.

Si bien se suele señalar por nuestra doctrina y tribunales que no existe ningún parámetro para que el juez chileno califique un daño de significativo $^{22}$-a diferencia de la

I. Municipalidad de Valdivia”, Rol 609/2007, $\mathrm{N}^{\circ}$ Legal Publishing: 38026, considerandos $26^{\circ}$ y $29^{\circ}$, redactada por el profesor Juan Andrés Varas.

${ }^{18}$ En la Directiva 2004/35/CE del Parlamento Europeo y del Consejo de 21 de abril de 2004 sobre responsabilidad medioambiental en relación con la prevención y reparación de daños medioambientales, se define, en el art. $2 \mathrm{n}^{\circ} 1$, al "daño medioambiental": a) los daños a las especies y hábitats naturales protegidos, es decir, cualquier daño que produzca efectos adversos significativos en la posibilidad de alcanzar o de mantener el estado favorable de conservación de dichos hábitats o especies...b) los daños a las aguas, es decir, cualquier daño que produzca efectos adversos significativos en el estado ecológico, químico o cuantitativo, o en el potencial ecológico definidos en la Directiva 2000/60/CE, de las aguas en cuestión, con excepción de los efectos adversos a los que se aplica el apartado 7 del artículo 4 de dicha Directiva; c) los daños al suelo, es decir, cualquier contaminación del suelo que suponga un riesgo significativo de que se produzcan efectos adversos para la salud humana debidos a la introducción directa o indirecta de sustancias, preparados, organismos o microorganismos en el suelo o el subsuelo".

${ }^{19}$ Sentencia J.L. Civ. Pto. Montt, 23.12.2002, “Fisco de Chile con Servitex S.A.”, Rol 2674-2000 (no apelada ni publicada): “... a juicio del Tribunal ha quedado demostrado que tal intervención ha producido un daño significativo en los términos que establece la Ley de Bases del Medio Ambiente, pues se ha afectado de manera importante recursos naturales que configuran el ecosistema del lago Coihuin, provocando la sedimentación del mismo y la erosión del suelo" (considerando $1^{\circ}$ ). En todo caso, en el mismo considerando, el juez consideró estos daños irreversibles y progresivos. Este fallo no fue apelado y no se encuentra publicado.

${ }^{20}$ En 'Vukasovic con Soc. Agrícola Sacor' (C. Ap. Stgo-2007), se señaló respecto de la gravedad del daño:”DÉCIMO: Que, en lo que se refiere a la aplicación de las normas de responsabilidad contenidas en la Ley $19.300 \ldots$, es preciso considerar los conceptos señalados en la misma, que permiten descartar en el presente juicio la existencia de un daño ambiental por faltar la relevancia, entidad, gravedad o significación de la contaminación que se atribuye a la demandada".

${ }^{21}$ Según expone el prof. Diez Schwerter, uno de los requisitos para configurar el daño como elemento de la responsabilidad civil es que tal daño consista en una turbación o molestia anormal, puesto que "la vida en sociedad implica ciertas limitaciones o molestias que es preciso soportar sin que pueda pretender obtener un resarcimiento por ellas" (...) "Criterio que nuestro legislador recientemente siguió en la Ley 19.300 ...al definir daño ambiental...” V. Diez, J. L., El daño extracontractual. Jurisprudencia y doctrina, Edit. Jurídica de Chile,

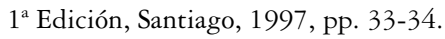

${ }^{22}$ La Corte Suprema cita textualmente al profesor Rafael Valenzuela: "Debido, por otra parte, a que la ley no contiene parámetros que permitan una calibración objetiva de la significación de los daños infligidos al medio ambiente, esta determinación queda entregada en definitiva a lo que resuelvan al respecto los jueces del fondo, con el margen de subjetivismo y de imprevisibilidad que ello conlleva. (Valenzuela, R. El Derecho 
reglamentación detallada de la Unión Europea ${ }^{23}$-, en realidad en Chile sí existen pero en la regulación del Sistema de Evaluación de Impacto Ambiental (SEIA). En efecto, para evaluar si un proyecto debe ingresar mediante un Estudio de Impacto Ambiental, varias causales deben analizarse según produzca o no el proyecto alteraciones significativas en base a criterios absolutamente transportables a la sede judicial.

Por ejemplo, para evaluar si un proyecto o actividad genera o presenta efectos adversos significativos sobre la "cantidad" y "calidad" de los recursos naturales renovables, incluidos el suelo, agua y aire (que son los daños ambientales más frecuentes en relación a las carreteras), el Reglamento del SEIA enlista más de 20 criterios (art. 6) ${ }^{24}$ y otro tanto ocurre para evaluar si el proyecto o actividad genera alteración significativa de los sistemas de vida y costumbres de grupos humanos (art. 8) o alteración significativa, en términos de "magnitud" o "duración”, del valor paisajístico o turístico de una zona (art. 10).

La labor del tribunal no será fácil pero al menos en las normas citadas podrá encontrar pautas o criterios, en los que, aparte de la cantidad, magnitud o duración del daño, deberá considerar su calidad, el valor ambiental de los recursos afectados, el servicio ambiental que prestan, su capacidad de regeneración y, obviamente, el carácter de recurso irremplazable, como ya lo ha advertido nuestra todavía escasa jurisprudencia ${ }^{25}$.

Ambiental, presente y pasado, Editorial Jurídica de Chile, 2010, pág. 318.)”. Ver en sentencia C.S., 20.04.2011, “Asoc. Canalistas Embalse Pitama con Soc. Concesionaria Rutas del Pacífico S. A.", Rol n 396-2009 (considerando. 20).

${ }^{23}$ En el Anexo I de la Directiva 2004/35/CE se entregan al juez criterios detallados de cuándo el daño es "significativo". Por ejemplo: los cambios adversos significativos en el estado básico de la fauna o flora deberían determinarse mediante datos mensurables como: "el número de individuos, su densidad o la extensión de la zona de presencia; el papel de los individuos concretos o de la zona dañada en relación con la especie o la conservación del hábitat, la rareza de la especie o del hábitat (evaluada en el plano local, regional y superior, incluido el plano comunitario); la capacidad de propagación de la especie (según la dinámica específica de la especie o población de que se trate); su viabilidad o la capacidad de regeneración natural del hábitat (según la dinámica específica de sus especies características o de sus poblaciones); la capacidad de la especie o del hábitat, después de haber sufrido los daños, de recuperar en breve plazo, sin más intervención que el incremento de las medidas de protección, un estado que, tan sólo en virtud de la dinámica de la especie o del hábitat, dé lugar a un estado equivalente o superior al básico".

${ }^{24}$ Como lo establecido en las normas de calidad y emisión chilenas (y si no existen, se podrán usar como referencia las vigentes en los Estados que se señalan en el artículo 7 del Reglamento); la composición, peligrosidad, cantidad y concentración de los efluentes líquidos, residuos y de las emisiones a la atmósfera; la frecuencia, duración y lugar de las descargas de efluentes líquidos y de emisiones a la atmósfera y dónde se manejan los residuos; la capacidad de dilución, dispersión, autodepuración, asimilación y regeneración de los recursos naturales renovables presentes en el área de influencia del proyecto o actividad (piénsese en la corta de araucarias); la cantidad y superficie de vegetación nativa intervenida y/o explotada, así como su forma de intervención y/o explotación; la cantidad de fauna silvestre intervenida y/o explotada, así como su forma de intervención y/o explotación y su estado de conservación (en peligro de extinción, vulnerables, raras o insuficientemente conocidas), la superficie de suelo susceptible de perderse o degradarse por erosión, compactación o contaminación, etc.

${ }^{25}$ Sentencia de primera instancia y C. Ap. Pto. Montt, 17.01.2007, "Fisco de Chile con Cía. Industrial Pto. Montt S.A.", Rol n 638-2006; comentadas en Ropert Fuentes, R., y Saavedra Fernández, R., "La protección del patrimonio cultural en la ley 19.300 de bases generales de medio ambiente a la luz de dos sentencias recientes", cit., pp. 191-221. Se señala por el juez de primera instancia: "El concepto de daño significativo, a juicio de este juez, no dice relación sólo con su aspecto físico o material, sino como resulta en el caso de autos, la alteración de elementos irremplazables y de contexto arqueológico o científico que posibilitan el estudio y análisis de dichos sitios arqueológicos...". (cons. 25, 26 y 27). 
En un reciente e ilustrado fallo (aún no firme), redactado por el prof. Daniel Peñailillo como abogado integrante de la Corte de Apelaciones de Concepción, se reitera que significativo corresponde a "importante" y se aclara que si bien se deben usar los criterios de "magnitud" o "duración" del daño (por emanar así de la historia de la ley) se trata de "expresiones disyuntivas, no copulativas" de tal manera que podría haber un daño de poca magnitud pero significativo igualmente, por ser permanente. Pero además se agregan tres criterios igualmente atendibles: en primer lugar, para calificar de significativo a un daño se debe considerar, independiente de su magnitud, "la representatividad del género al que pertenece el componente afectado" (por ejemplo, la corta de especies protegidas); segundo, que aun cuando algunos daños específicos acreditados pudieren considerarse de poca envergadura o sean de aquellos que se deben tolerar por la vida en sociedad, cuando se estiman en conjunto, resultan claramente significativos; y, en tercer lugar, resolviendo el caso concreto revisado, tendría también ese carácter el daño cuando afecte fuentes de agua de consumo humano pues puede afectar la salud de las personas, fundándose en que "en la historia de la ley 19.300 queda de manifiesto que esta circunstancia siempre se consideró destacadamente relevante dentro del conjunto de daños ambientales" 26 .

En otro fallo del 2011, también alusivo a la "magnitud" como criterio de evaluación del daño significativo, la Excma. Corte Suprema señaló: "Contrariamente a lo manifestado por los juzgadores, no resulta ser un factor determinante en la constatación del daño denunciado en estos autos la magnitud del volumen de las aguas extraídas desde los pozos que operaba la demandada y su posterior cotejo con la extracción total de aguas que realizan terceros en los acuíferos antes mencionados". Para calificar de significativo a un daño debe acudirse a "una calibración de la significación de los deterioros infligidos a aquél" como que, en el caso concreto, "la cuenca de la Pampa del Tamarugal es un ecosistema particularmente vulnerable dada la escasez de agua y del cual dependen otros componentes ambientales, como el suelo, flora y fauna". (considerando 7$)^{27}$.

Específicamente, en materia de daño ambiental y autopistas, la Excma. Corte Suprema, también en el año 2011, acogió la demanda en el caso del Embalse Pitama, haciéndose cargo de fundamentar por qué estimó el daño como significativo pese que la perito judicial informante en autos desarrolló técnicamente los fundamentos para señalar que el menoscabo causado al medio ambiente no calificaba de "daño ambiental" por "no superar los límites máximos permitidos por la legislación”, lo cual a nuestro juicio es un error inaceptable de la profesional pues claramente en nuestra legislación puede haber daño sin contaminación y contaminación sin daño. La superación de una norma (como exige el concepto legal de "contaminación” en la LBGMA) no es un requisito del daño en el régimen de la $\mathrm{LBGMA}^{28}$.

\footnotetext{
${ }^{26}$ Sentencia C. Ap. Concepción, 15.09.2011, "Fisco de Chile con Servicio de Vertederos Los Maitenes", Rol 493-2011.

${ }^{27}$ V. Sentencia C.S., 28.10.2011, "Fisco de Chile con Sociedad Contractual Minera Compañia de Salitre y Yodo Soledad", Rol 5826-2009 (cons. $7^{\circ}$ ).

28 Corral, H., "Daño ambiental y responsabilidad civil del empresario en la ley de bases del medio ambiente", cit., p. 167.
} 
Pues bien, la Corte, razonando en otra línea, señaló: “...para evaluar la significación del daño ambiental no sólo deben considerarse parámetros técnicos que justiprecien el grado de contaminación específica en un momento dado de un determinado recurso natural, sino que debe analizarse cómo la conducta acreditada generará con certeza un daño que pueda ser calificado de significativo. Tal criterio se basa en que no resulta razonable esperar un mayor, grave e irrecuperable resultado lesivo para hacer lugar a una acción medioambiental que busca mitigar y reparar los efectos perjudiciales de una conducta que sí afecta el medio ambiente de manera relevante y, por lo mismo significativa, cuando el propósito del legislador es precisamente la prevención de su acaecimiento”. Agrega que "se encuentra acreditado que la conducta negligente de la demandada perturba y amenaza de forma cierta y precisa con seguir intensificando la afectación de la calidad de las aguas del Embalse Pitama, puesto que el sistema de drenaje o saneamiento del botadero resulta ineficaz, así como también es insuficiente la implementación de los programas de revegetación y reforestación del mismo..." y que "queda demostrada la relación de causalidad entre la conducta imputada a la demandada y el perjuicio originado al medio ambiente, que consistirá precisamente en la desaparición del Embalse Pitama. Por estas razones debe calificarse que la conducta de la demandada ha causado un daño ambiental significativo y que concurriendo relación de causalidad con la conducta de la demandada, debe ser reparado" 29.

Como vemos, nuestro máximo Tribunal, obviando que en términos legales no había contaminación, evaluó el carácter de significativo del daño, tomando en consideración no sólo los efectos ya existentes en el embalse, sino su futura desaparición, efecto que consideró cierto y significativo.

\section{Normas aplicables}

Existiendo un daño ambiental en los términos señalados, se aplica el régimen de los arts. 51 y siguientes de la LBGMA, a menos que existan normas legales de responsabilidad civil extracontractual especiales ${ }^{30}$. En todo lo no regulado por las leyes especiales, rige el régimen especial de la LBGMA y, en lo no regulado por él, el título (y sólo ese) XXXV del Código Civil (arts. 2314 y siguientes). De hecho, la jurisprudencia ya ha aplicado en materia de daño ambiental la regla de solidaridad contenida en el art. 2317

29 Sentencia C.S., 20.04.2011, "Asoc. Canalistas Embalse Pitama con Soc. Concesionaria Rutas del Pacífico S.A.", Rol n 396-2009 (considerando 30).

${ }^{30}$ Estas leyes especiales están indicadas en el completo artículo del Prof. Hernán Corral, escrito sólo a dos años de la dictación de la LBGMA, "Daño Ambiental y Responsabilidad Civil del empresario en la Ley de bases del medio ambiente”, cit., p. 149, quien además se encarga de desarrollar listados de normas de carácter reglamentario que por su rango inferior no podrían aplicarse con preferencia al régimen de responsabilidad de la LGBMA; y cuestiona la aplicación de ciertas legislaciones más generales que tendrían incidencia tangencial en materias ambientales (V/gr.: Ley de Tránsito, Ley General de Urbanismo y Construcciones; Ley Orgánica de Municipalidades), en la p. 150. 
del $\mathrm{CC}^{31}$, que perfectamente podría aplicarse, en el tema que nos ocupa, contra la concesionaria y el Estado.

Fundamental entonces resulta determinar si la normativa que abreviaremos como Ley de Concesiones (Decreto 900 MOP, 18 de diciembre de 1996, fija texto refundido, coordinado y sistematizado del D.F.L. N 164 MOP, de 1991, Ley de concesiones de obras públicas) establece o no reglas distintas de responsabilidad civil extracontractual por daño ambiental. Para eso básicamente debemos revisar su art. 35, pues de lo que no cabe duda es que la norma del art. 62 de su Reglamento ${ }^{32}$, que se refiere expresamente al daño al medio ambiente, por su rango inferior, no podría primar sobre la LBGMA si se estimara que establece una regla distinta a ella. La norma reglamentaria indicada impone a la concesionaria responder de "todo daño al medio ambiente" (como es en el derecho común), a diferencia de la exigencia que impone la LBGMA de tener que ser una afectación "significativa", idea que se desarrolla en el caso del daño ambiental al embalse Pitama ${ }^{33}$; o bien, cuando establece un seguro obligatorio de responsabilidad civil extracontractual, pues aparte de estar en el reglamento, él es obligatorio sólo para daños a terceros y situaciones catastróficas (art. 36).

Pues bien, el art. 35 de la ley de Concesiones establece: "El concesionario responderá de los daños, de cualquier naturaleza, que con motivo de la ejecución de la obra o de la explotación de la misma se ocasionaren a terceros, a menos que sean exclusivamente imputables a medidas impuestas por el Ministerio de Obras Públicas, después de haber sido adjudicado el contrato". Somos de la opinión que en esta norma no se establece régimen de responsabilidad civil extracontractual especial alguno, más que una regla de legitimación pasiva, cuestionable por lo demás, que indica los casos en que la concesionaria “o” el Estado serán responsables.

${ }^{31}$ Se condenó solidariamente a un particular y a la I. Municipalidad de Antofagasta por la demolición de la llamada casa de Huéspedes. Ver en sentencia C. Ap. Antofagasta, 19.04.2004, "Fisco de Chile con Sociedad Química y Minera de Chile" (revoca la de 1er grado), Rol n 16.391; Sentencia C.S., 30.08.2006, "Fisco de Chile con Sociedad Química y Minera de Chile” (acoge casación, confirma la de 1er grado), Rol n 1.911-2004, Id. Legal publishing $\mathrm{n}^{\circ} 35145$.

32 El que abreviaremos como Reglamento de la Ley de Concesiones (Reglamento del D.F.L. MOP 164, de 1991, modificado por las Leyes 19.252 de 1993 y 19.460, de 1996, contenido en Decreto 956 del MOP de 6 de octubre de 1996, publicado en el Diario Oficial de 20 de marzo de 1999), en su art. 62, señala: "DAÑOS A TERCEROS: 1.- La sociedad concesionaria deberá adoptar, durante la concesión, todas las medidas para evitar daños a terceros y al personal que trabaja en la obra. Igualmente deberá tomar todas las precauciones para evitar daños a la propiedad de terceros y al medio ambiente durante la concesión de la obra. 2.- La sociedad concesionaria será la única responsable de todo daño, de cualquier naturaleza, que con motivo de la ejecución de la obra y de su explotación se cause a terceros, al personal de la obra, a la propiedad de terceros o al medio ambiente, a menos que el daño sea exclusivamente imputable a medidas impuestas por el MOP después de la publicación del decreto supremo de adjudicación en el Diario Oficial".

${ }^{33}$ En efecto, en la sentencia de la Corte Suprema en el caso Pitama se señala: “... en lo referido a las acciones que contempla la legislación especial, dado que expresamente se ha consignado la vigencia del derecho común ante perjuicios no comprendidos en la definición de daño ambiental, a la cual se ha hecho referencia, que limita fundamentalmente al de carácter significativo. Sin embargo, teniendo en cuenta que la legislación común ordena reparar todo daño (art. 2329 del Código Civil), queda entregada a ella la regulación de esta materia en forma subsidiaria, esto es, cuando el daño no sea significativo”. (considerando 19). Sentencia C.S., 20.04.2011, “Asoc. Canalistas Embalse Pitama con Soc. Concesionaria Rutas del Pacífico S. A.”, Rol n 396-2009. 
De hecho, sólo en base al tenor literal de esta norma se rechazó una acción ordinaria de perjuicios morales y acciones materiales (respecto a un daño al medio ambiente) interpuesta contra el Estado y la concesionaria, en la parte que lo era contra éste ${ }^{34}$.

En todo caso, si se revisan las bases de licitación, se constata que en todas ellas, especialmente las últimas, el MOP fija las reglas del juego incluyendo expresamente el art. 35 y además repite, varias veces, que la responsabilidad de dar cumplimiento a las medidas y/o exigencias ambientales contenidas en la resolución de calificación ambiental (en adelante RCA) serán de exclusiva responsabilidad de la concesionaria. Ella será -precisa- "la única responsable ante la autoridad ambiental y cualquier otra autoridad pública del cumplimiento de las medidas y exigencias ambientales". Incluso más, se considera como incumplimiento "grave" el hecho de no ingresar el proyecto al SEIA o el incumplimiento reiterado de las obligaciones medioambientales contenidas en el Estudio de Impacto Ambiental (en adelante, EIA), Declaración de Impacto Ambiental (en adelante, DIA), según corresponda y sus Adendas, en las Bases de Licitación y las RCA; y se señala que este grave incumplimiento es causal de extinción de la concesión.

Sin perjuicio de lo que se dirá respecto al alto estándar de conducta exigido a las concesionarias en el cumplimiento de sus obligaciones ambientales para los efectos de la apreciación de su culpa, por ahora precisemos que si se ocasiona un daño por el actuar o la omisión de la concesionaria debe aplicarse el régimen común de la LBGMA y, en lo no regulado por ella, el título XXXV del Código Civil: se puede ejercer la acción ambiental, para solicitar la reparación material del medio ambiente dañado, sin perjuicio de las acciones ordinarias por los directamente afectados. Revisaremos entonces el régimen común de la LBGMA, con su modificación del año 2010 y su reforma, con la futura ley de los Tribunales Ambientales ${ }^{35}$, pero a la luz del régimen de concesiones.

\section{LAS ACCIONES CIVILES PARA EXIGIR LA REPARACIÓN DEL DAÑO AMBIENTAL}

En sus arts. 51 y ss, claramente la ley distingue entre las llamadas por la doctrina "acción ambiental" y "acción ordinaria". El art. 53 claramente señala: "Producido daño ambiental, se concede acción para obtener la reparación del medio ambiente dañado, lo que no obsta al ejercicio de la acción indemnizatoria ordinaria por el directamente afectado". El art. 51 obliga a responder en conformidad a esta ley a "todo aquel que culposa o dolosamente cause daño ambiental” y el art. 3, fuera del título que estamos revisando, reitera que "todo el que culposa o dolosamente cause daño al medio ambiente, estará obligado a repararlo materialmente, a su costo, si ello fuera posible, e indemnizarlo en conformidad a la ley".

${ }^{34}$ Sentencia $21^{\circ}$ J.L. Civ. Santiago, 19.05.2006, “Aguilera Adela Rosa con Ministerio de Obras Públicas y Rutas del Pacífico S.A.”, rol n 760-2006; confirmada parcialmente por C. Ap. Santiago, 11.06.2009, Rol n 6.4402006; C.S. rechaza casación, 29.12.2009, Rol n 6.793-2009.

${ }^{35}$ No abordaremos por ahora algunas reformas importantes del proyecto, como el procedimiento, la institución del amicus curiae, las medidas prejudiciales y especialmente las cautelares. 
Respecto a la acción ordinaria, por muchos se estimaba que esta acción se regía por el derecho común y que, en consecuencia, no podía ejercerse conjuntamente con la acción ambiental pues se rigen por procedimientos distintos (ordinario y sumario, respectivamente $)^{36}$. Sin embargo, hay varios casos en que se han ejercido ambas acciones en una misma demanda sin mayores complicaciones, como en el caso Pitama, recientemente resuelto por la Corte Suprema, en que se condenó a reparar materialmente el daño ambiental y, además, a indemnizar los daños a los personalmente afectados.

Esta situación dejará de darse pues el proyecto de ley de los Tribunales Ambientales establece procedimientos y tribunales diferentes para cada una de las acciones. Señala que la declaración del daño ambiental y la condena al demandado a repararlo se reflejarán en la sentencia definitiva que dicte el Tribunal Ambiental, mientras que la indemnización de perjuicios por el daño ambiental que haya declarado este Tribunal se determinará por el Juzgado de Letras en lo Civil que tenga competencia en el lugar donde se haya producido el daño. Agrega el art. 46 que este juzgado civil, al resolver sobre la indemnización de perjuicios, se basará en el daño ambiental y la relación causal entre éste y la acción del ofensor establecidas por el Tribunal Ambiental. Se exige entonces que antes de ejercer la acción ordinaria se ejerza la acción ambiental.

Por otra parte, hay dos casos en que no se puede ejercer la acción por daño ambiental ${ }^{37}$.

\section{Procedimiento y prueba en la “acción ambiental”}

A partir de la Ley 20.417, fueron derogadas varias normas de la LBGMA (relativas al procedimiento sumario, aceptación de todos los medios de prueba, apreciación según la sana crítica etc.), algunas de las cuales afortunadamente se mantienen en el proyecto de ley sobre Tribunales Ambientales.

\footnotetext{
${ }^{36}$ Sin embargo, si la "acción ordinaria” reclama por los daños en el patrimonio, la salud o vida de las personas que nace de un daño ambiental, no vemos por qué no beneficiar a esta acción con las normas de la LBGMA (como procedimiento sumario, apreciación de la prueba según las reglas de la sana crítica, uso de cualquier medio de prueba etc.) cuando en el fondo, desde el punto de vista práctico, quien demande la reparación de su daño deberá también probar los elementos de la responsabilidad del daño ambiental puro.

37 Cuando los responsables de fuentes emisoras sujetas a planes de prevención o descontaminación acreditaren estar dando íntegro y cabal cumplimiento a las obligaciones establecidas en tales planes, sólo cabrá la acción indemnizatoria ordinaria deducida por el personalmente afectado, a menos que el daño provenga de causas no contempladas en el respectivo plan (art. 55). Además, en virtud de la reforma de la Ley 20.417, "no procederá la acción para obtener la reparación del medio ambiente dañado cuando quien cometió el daño ejecutó satisfactoriamente un plan de reparación aprobado por la Superintendencia de Medio Ambiente" (art. 53), suspendiéndose, en este caso, el plazo de prescripción de la acción (art. 43 Ley 20.417). En caso que iniciado un expediente sancionatorio por la Superintendencia de Medio Ambiente y se acreditare la existencia de un daño ambiental, si el infractor no presentare voluntariamente un plan de reparación, el Estado será el único legitimado para ejercer la acción ambiental como parte principal (art. $18 \mathrm{n}^{\circ} 2$ del proyecto). No se soluciona en esta nueva norma el caso en que presentado y aprobado el plan no se ejecute luego satisfactoriamente, manteniéndose todo o parte del daño ambiental.
} 
Cabe señalar que esta acción ya no se tramitará según el procedimiento sumario, sino de acuerdo a un procedimiento especial, con audiencias verbales y etapas escritas.

La prueba se seguirá apreciando de acuerdo a las reglas de la sana crítica (art. 35), se seguirá aceptando cualquier medio de prueba obtenido por medios lícitos y especial importancia sigue teniendo el informe pericial (art. 42), donde ya no sólo las partes podrán solicitarlo sino también el tribunal podrá decretar su práctica, sin perjuicio del derecho de las partes a designar un perito adjunto, que podrá estar presente en todas las fases del análisis pericial.

\section{PRESCRIPCIÓN Y RETROACTIVIDAD}

Hay una excelente norma de prescripción (art. 53) aplicable tanto a la acción ambiental como a las otras acciones civiles (entendemos la ordinaria) en base a la cual estas acciones prescribirán en el plazo de cinco años, contados desde la manifestación evidente del daño. Sin embargo, para los daños al recurso suelo-que puede darse en el tema que analizamos- el plazo se sigue considerando escueto ${ }^{38}$ y además, en la práctica, ha habido algunos problemas para determinar cuándo existe esta manifestación "evidente", debiendo estarse, a nuestro juicio, a análisis, peritajes o documentos de la autoridad, que constaten la afectación o tomen alguna medida dado su carácter negativo para el medio ambiente o la salud de las personas, aunque no lo califiquen de daño ambiental ${ }^{39}$.

En materia de retroactividad, a diferencia de la mayoría de las normas en derecho comparado, la LBGMA reguló los efectos retroactivos de sus disposiciones ${ }^{40}$. En todo caso, ni la doctrina ni la jurisprudencia se han percatado de esta norma y, en la práctica,

${ }^{38}$ Es una de las críticas que hace José Agustín Ramírez respecto de la aplicación de la normativa a los problemas históricos sobre contaminación de suelos: "[e]l plazo de prescripción de la acción de 5 años desde la manifestación evidente del daño es una limitante objetiva que provocará la imposibilidad de iniciar importantes acciones restauradoras". V. Ramírez S., J., "La contaminación y daño al suelo y subsuelo en la legislación chilena y comparada”, en Revista de Derecho, Consejo de Defensa del Estado, vol. 1, N 1, 2000, p. 137.

${ }^{39}$ Sentencia C. Ap. Arica, 27.08.2007, "Cristina Martínez González y otros con Sociedad Procesadora de Metales Promel Ltda., Fisco de Chile y otros”, Rol 681-2007, Considerando 11: "Al efecto, es dable precisar que el Juez de Grado, rechaza la prescripción impetrada, sobre la base del artículo 63 de la ley 19.300 que establece un plazo especial de cinco años para las acciones de daño. El criterio del juzgador debe entenderse en términos que el daño evidente, esto es, la expresión material del daño ambiental, ocurre en el año 1997, fecha en que la autoridad sanitaria tomara las medidas al efecto del acopio (Ord. N 215 y 3252 del Servicio de Salud de Arica), esto es, cuando se ordenó el traslado de los residuos tóxicos al sitio definitivo".

${ }^{40}$ El art. 6 transitorio de la LBGMA señala: "Lo dispuesto en el artículo 3 se aplicará a contar de los noventa días siguientes a la publicación de la presente ley". A su vez, esta norma dispone: "Sin perjuicio de las sanciones que señale la ley, todo el que culposa o dolosamente cause daño al medio ambiente, estará obligado a repararlo materialmente, a su costo, si ello fuere posible, e indemnizarlo en conformidad a la ley". 
suele el tema confundirse con el de la prescripción ${ }^{41}$ y, entonces, se alega la aplicación del art. 25 de la Ley de Efecto Retroactivo ${ }^{42}$.

\section{Formas DE REPARACIÓN}

La acción ambiental se concede para obtener la reparación del medio ambiente dañado, reparación que es material, in natura, en "moneda verde", por la propia definición que la ley da de esta expresión.

La ley es realista y estima cumplida la obligación de reparar cuando al menos el condenado logra "reponer el medio ambiente o uno o más de sus componentes a una calidad similar a la que tenían con anterioridad al daño causado o, en caso de no ser ello posible, restablecer sus propiedades básicas". (art. 2 letra s). La imposibilidad técnica de lograr restablecer la calidad similar a la que alude la ley es imprescindible para que baste sólo restablecer sus propiedades básicas.

Ninguna otra imposibilidad puede alegarse para no cumplir las obligaciones (generalmente de hacer) que deben ejecutarse en el lugar del daño, como se ha pretendido, alegándose que por no ser dueño del lugar (sino mero arrendatario) existe una imposibilidad de realizar labores de reparación en suelo ajeno ${ }^{43}$.

Cuando el daño es irreversible, la LBGMA no reguló a qué se condenará al demandado. Por ello y dado el tenor del art. $3^{\circ}$ se resolvió en dos casos del año $2002^{44}$ y

${ }^{41}$ Fallo C.S., 9 de septiembre de 2010, "Fisco de Chile con Compañía Minera Santa Laura Limitada", Rol 7749-2008. La demandada solicitaba contar el plazo de prescripción desde que entró en operaciones (1981) o con la entrada en vigencia de la LBGMA. Sin embargo, la C.S señaló que “...no resulta procedente aplicar la prescripción pedida, por no resultar posible establecer en forma determinada la primera manifestación evidente del daño, el que ha seguido produciéndose". (considerando $6^{\circ}$ ).

${ }^{42}$ Véase la discusión acerca de la aplicación del art. 25 de la Ley de Efecto Retroactivo, en Sentencia C. Ap. Arica, 27.08.2007, "Cristina Martínez González y otros con Sociedad Procesadora de Metales Promel Ltda., Fisco de Chile y otros”, Rol 681-2007.

${ }^{43}$ La Corte Suprema, en fallo de 25 de enero de 2006, resolvió: “14) Que el artículo tercero [LBGMA] tantas veces mencionado, coloca al causante del daño en la obligación de repararlo materialmente, y agrega, "si ello fuere posible", desde luego, y contrariamente a lo que sostienen los jueces del mérito, se refiere justamente a la imposibilidad de efectuar materialmente la reparación material del daño, atendida la naturaleza y entidad de éste, pero en ningún caso a situaciones ajenas, como si el demandado es dueño o no de la propiedad donde éste se cometió. La ley al establecer la obligación de reparación no distingue si quien causó el daño es dueño o no del lugar donde éste se produjo. Entonces, si el demandado es o no en este caso propietario del predio donde se causó el daño y por ende, deben realizarse las faenas necesarias para su reparación material, carece de importancia para los efectos de aplicársele las sanciones que correspondan, así como para ordenarle ejecutar o realizar las medidas tendientes a lograr la reparación material. Sólo puede cobrar importancia esta materia al momento de intentarse el cumplimiento o ejecución de la sentencia que imponga tales cargas, lo que, de plantearse, deberá ser resuelto en esa etapa". V. Sentencia C.S., 25.01.2006, "Fisco de Chile con Juan Boezio Sepúlveda", Rol n 4892006 (casación, cons. $14^{\circ}$, y con voto disidente).

44 "Que si la reparación descrita no es posible, surge en forma subsidiaria la obligación de indemnizar el daño producido, situación que si bien no se señala expresamente en la ley 19.300, se deduce por aplicación supletoria de las normas civiles de responsabilidad extracontractual, en especial el art. 2314 del Código Civil”. (considerando 31 del fallo de primera instancia de 19 de diciembre de 2002, confirmado en segunda instancia, 
luego fue argumentado por la doctrina ${ }^{45}$ que cuando el daño es irreparable procede la indemnización, en base a la aplicación supletoria del título XXXV del Código Civil, que considera la posibilidad de reparar en especie o en dinero, acogiéndose en definitiva la tesis por la Corte Suprema ${ }^{46}$.

Sin embargo, esta solución -que es a todas luces justa respecto al condenado- tiene como desventaja que los fondos no tendrán un fin ambiental. Por ello -advierte Vidal- "el titular de esta indemnización debiese ser el Estado como garante del derecho fundamental garantizado a todos por la Constitución, o bien el órgano de la Administración del Estado al que la Ley ha encomendado concretamente el cumplimiento de deber estatal de la preservación del medio ambiente. Así como en el caso de la indemnización del seguro ambiental del artículo 15, la indemnización debiese ingresar al Fondo de Protección Ambiental del artículo de la Ley. Es el Estado y sus órganos, en virtud del mandato constitucional, los que deben velar por el correcto destino que se asigne a las indemnizaciones de daño ambiental (artículo 68 Ley 19.300). De lo anterior se sigue que si es cualquier persona afectada por el daño ambiental que demanda su indemnización de daños en forma subsidiaria, deberá pedirlo a beneficio del Estado o del Fisco y no al propio, dado que ello implicaría un enriquecimiento sin causa" ${ }^{4}$.

Creo que el espíritu y la historia de la LBGMA sólo consideraba la reparación material y que, en consecuencia, en los casos en que la reparación no sea posible, se debiera "compensar" el daño - como ya se ha sugerido ${ }^{48}$ - pero en los términos técnicos definidos por la LBGMA y su reglamento, es decir, condenar a hacer algo que "tenga por finalidad producir o generar un efecto positivo alternativo y equivalente a un efecto adverso identificado" (art. 60 del Reglamento) y que -como agrega el art. 61- se haga "en el mismo lugar o área" del daño que se trata de compensar. Si los daños irreparables se "compensan" en el SEIA, lo ideal sería aplicar esta regla también aquí.

Pese a estas sugerencias, la ley de tribunales ambientales omitió toda referencia al tema.

rebajando el monto de la indemnización por C. Ap. Pto. Montt, 17.01.2007, "Fisco de Chile con Cía. Industrial Pto. Montt S.A.", Rol n 638-2006); comentadas ambas en Ropert Fuentes, R., y Saavedra Fernández, R., "La protección del patrimonio cultural en la ley 19.300 de bases generales de medio ambiente a la luz de dos sentencias recientes”, cit., pp. 191-221. Este considerando 31 es idéntico al considerando 18 del fallo (no publicado) dictado por el juez (s) Juan Carlos Silva Opazo, el día 23 de diciembre de 2002, Sentencia $2^{\circ}$ J.L. Civ. Pto. Montt, 23.12.2002, "Fisco de Chile con Servitex S.A.", Rol 2674-2000.

${ }^{45}$ Destacan que procede la indemnización (o la compensación) en el caso de los daños irreparables Figueroa E.-Asenjo R.-Valdés S.-Praus, S. "La responsabilidad civil ambiental, el daño al medio ambiente y su valor: una aproximación legal y económica", en Revista de Derecho Ambiental, Centro de Derecho Ambiental, Universidad de Chile, N², 2006, pp. 69-95; y Vidal, A. "Las acciones civiles derivadas del daño ambiental en la ley n 19.300", en Revista de Derecho, P. Universidad Católica de Valparaíso, XXXIX (2do sem.) 2007, p. 138.

${ }^{46}$ Sentencia C.S., 31 de agosto de 2010, "Fisco de Chile con Forestal Candelaria de Río Puelo S.A. y otros", Rol 5027-2008 (citando a Vidal O.), por la corta de 25 alerces de más de 3.000 años.

${ }^{47}$ V. Vidal O., Álvaro, "Las acciones civiles derivadas del daño ambiental en la ley n 19.300 ”, cit., p. 138.

48 Propusieron "compensar" los daños irreparables Figueroa, E.-Asenjo, R.-Valdés, S.-Praus, S. "La responsabilidad civil ambiental, el daño al medio ambiente y su valor: una aproximación legal y económica”, cit., pp. 69-95. 


\section{LEGITIMACIÓN ACTIVA49}

Por otra parte, si la acción ambiental tiene por objeto sólo la reparación material, no hay obstáculos en que la legitimación activa sea amplia, como de hecho se consideraba en el proyecto de ley, en que la acción era popular, siguiendo una clara tendencia del derecho comparado y de nuestro Código Civil. Sin embargo, en definitiva, primaron los infundados temores acerca de este instrumento (al que se le han fijado límites en el derecho comparado) y en definitiva tenemos una legitimación activa muy restringida, que estimo constituye una de las razones del fracaso del sistema, considerando la cantidad de daños existentes versus las acciones presentadas.

Los legitimados, de acuerdo al art. 54, son el Estado, las Municipalidades y los que hayan "sufrido" el daño.

El Estado está legitimado para accionar a través del Consejo de Defensa del Estado (CDE), que cuenta con una Unidad de Medio Ambiente, que ha realizado una excelente labor por años pero que sufre la delicada complicación que el mayor causante de daños ambientales en Chile quizás sea el Estado o entes relacionados, concordando entonces con Bermúdez en que un juicio de Fisco contra Fisco parece un contrasentido ${ }^{50}$ y con Bordalí, en la falta de independencia del CDE del Ejecutivo ${ }^{51}$. No conocemos casos en que el Consejo haya demandado al Estado en sentido estricto, aunque sí solidariamente a un particular y a una Municipalidad ${ }^{52}$.

Las Municipalidades pueden accionar por los hechos "acaecidos" en sus comunas, aunque en realidad debiera ser aquella en que se producen los efectos dañosos. Lamentablemente ellas, por regla general, no tienen ni los recursos humanos ni financieros para asumir este tipo de acciones.

Finalmente, pueden ejercer la acción ambiental las personas naturales y jurídicas, de derecho público o privado, que hayan "sufrido el daño", a las que, casi siempre, les interesará solo perseguir la reparación de "su" daño y no la del daño ambiental, respecto del cual deberán asumir un juicio largo, caro, técnicamente difícil, generalmente contra grandes empresas etc. De hecho, en materia de daño ambiental y concesionarias, conocemos sólo el caso del embalse Pitama, en que junto al daño personal se demandó la reparación del daño ambiental. Esta situación cambiará pues la ley de tribunales ambientales opera bajo el supuesto de que primero debe determinarse el daño ambiental

${ }^{49}$ Para este tema, se recomienda, De la Barra, F., "Responsabilidad extracontractual por daño ambiental: el problema de la legitimación activa", en Revista Chilena de Derecho, P. Universidad Católica de Chile, vol. 29 $\mathrm{N}^{\circ}$ 2, 2002, pp. 367-415.

${ }^{50}$ Los argumentos en Bermúdez, J., "La responsabilidad extracontractual de la administración del Estado por falta de servicio y por el daño ambiental”, en Revista de Derecho, P. Universidad Católica de Valparaíso, XXIII (Valparaíso, Chile, 2002), 245-256.

${ }^{51}$ V. Bordalí, A., Tutela jurisdiccional del medio ambiente, Editorial Fallos del Mes, Santiago, 2004, p. 296.

52 Ver en sentencia C. Ap. Antofagasta, 19.04.2004, "Fisco de Chile con Sociedad Química y Minera de Chile" (revoca la de 1er grado), Rol n 16.391; Sentencia C.S., 30.08.2006, "Fisco de Chile con Sociedad Química y Minera de Chile” (acoge casación, confirma la de 1er grado), Rol n 1.911-2004, Id. Legal publishing n 35145. 
por el tribunal ambiental y luego se podrá recurrir al juez de letras correspondiente a reclamar los daños personales.

Si bien en el inciso $2^{\circ}$ del art. 54 podría pensarse que existe una especie de "acción popular" ella no es más que una simple petición, que no hace al solicitante parte en el juicio y que podrá generar, a lo más, responsabilidad solidaria de la Municipalidad, respecto a los daños personales del peticionario (y no al daño ambiental puro), siempre y cuando además se cumplan varias condiciones ${ }^{53}$.

Si se solicita sólo reparación in natura -reitero- no veo razones para no aceptar al menos que puedan accionar las Organizaciones No Gubernamentales (ONG) del lugar del daño y que contengan en sus estatutos la defensa del medio ambiente. Considerando el carácter colectivo de los efectos de los daños al medio ambiente y los efectos erga omnes que causa la sentencia que resuelva el juicio, estas personas -utilizando la errónea ${ }^{54}$ expresión de la LBGMA y que se repite en el proyecto de tribunales ambientales- han también "sufrido" el daño ambiental puro, colectivo o público. Sin embargo, hasta la fecha, la jurisprudencia exige la lesión en el patrimonio, salud, etc., del accionante.

Otro error evidente de la ley fue establecer, en el inciso final de la misma norma, que interpuesta la acción ambiental por alguno de los legitimados "los demás sólo podrán ser terceros" y si bien la doctrina estimaba que eran terceros "coadyuvantes”, el CDE con éxito actuó como tercero independiente. ${ }^{55}$ La futura ley de tribunales ambientales limita la intervención expresamente a terceros coadyuvantes (art. $18 \mathrm{n}^{\circ} 2$ ).

Tampoco estableció nuestra ley, como en Brasil, Uruguay, el Código Procesal Modelo para Iberoamérica, etc., que si la acción se pierde por falta de pruebas o desistimiento del actor, no habrá cosa juzgada y podrá perfectamente volver a ejercerse la acción, incluso por el mismo actor si hay nuevas pruebas ${ }^{56}$, norma que debe acompañar a las acciones relacionadas con los llamados derechos o intereses colectivos o difusos.

${ }^{53}$ Cualquier persona puede pedir a la Municipalidad -aportándole antecedentes- que presente una demanda por daño ambiental. Pero si la Municipalidad demanda, su petición no la hará parte del juicio. Además, ella a lo más genera en la Municipalidad la obligación de, en cierto plazo, accionar o responderle mediante resolución fundada por qué no va a demandar. Si no lo hace, se hace solidariamente responsable pero sólo de los daños al directamente afectado. De esta manera, si el solicitante no es el afectado, la entidad edilicia podrá, sin consecuencias, no presentar la demanda y ni siquiera contestarle, sin mayores consecuencias.

54 En ese sentido, Rafael Valenzuela plantea que la LBGMA “yerra” pues la víctima de este daño "no sería una persona determinada, sino que el medio ambiente, en su globalidad, o uno o más de sus componentes, considerados en cuanto tales". Valenzuela, R. "Responsabilidad Civil por Daño Ambiental en la Legislación Chilena”, cit., págs. 3-19.

55 Sentencia C. Apelaciones Antofagasta, 03.03.2008, "Sindicato de Pescadores de Artesanos con Shell Chile S.A.C.I. y otro", Rol n 340-2007 (cons. $3^{\circ} ; 11^{\circ}-12^{\circ}$ ). El CDE logró incluir en la condena de reparación material, las medidas por él propuestas, distintas a las solicitadas por la parte principal.

56 Una característica importante de la acción popular brasileña es el régimen especial establecido en relación a los efectos de la cosa juzgada: la sentencia que acoja la demanda o la rechace por no existir fundamento producirá efectos erga omnes impidiendo una nueva acción, por igual fundamento; pero si lo pedido fue rechazado por insuficiencia de pruebas, la sentencia no producirá cosa juzgada, pudiendo ser renovada por otra acción (del mismo actor popular o cualquier otro ciudadano) con igual fundamento, dentro del plazo de 5 años, siempre que se indiquen nuevas pruebas (art. 18 de la Ley 4717 de 20 de junio de 1965). Esta norma sirvió de modelo a la acción civil pública brasileña, también aplicable en materia ambiental y para el Código modelo para Iberoamérica de 
Esta situación genera una serie de problemas que pueden darse cuando el afectado personal demanda la reparación del daño ambiental puro y no lleva el juicio de una manera adecuada; o bien negocia con el causante del daño, para demandarlo rápidamente por el daño ambiental puro y luego se desiste o pierde dolosamente el juicio por falta de pruebas (a cambio de una reparación cuantiosa y rápida de su daño). El CDE -que representa al Estado y a todos nosotros, en consecuencia- sólo podrá ser tercero y la sentencia lo obligará si no logra preparar el juicio rápidamente. La situación empeoraba si tal como ha transado el CDE (velando por el interés público) transaba ahora este particular afectado pues no hay ninguna prohibición al respecto ni tampoco la exigencia de ser aprobada esta transacción por el propio CDE, el Ministerio del Medio Ambiente o, como en otras latitudes, la Fiscalía del Medio Ambiente o el Defensor del Pueblo, asegurando así que los intereses generales queden resguardados.

\section{LA TRANSACCIÓN EN LOS JUICIOS POR DAÑO AMBIENTAL}

Según la información disponible años atrás en la página del CDE, el organismo en el año 2000 habría transado con Gas Atacama por el daño a un sitio arqueológico, en 120 millones de pesos destinados, 90 en restauración y 30 para capacitación de las comunidades atacameñas; y con la Curtiembre Stolzenbach y Cía. Ltda., por vertimiento de riles al río Calle Calle, obligándose la empresa a dragar $20 \mathrm{~cm}$. del lecho del río para retirar metales pesados, tomar muestras de lo retirado e implementar una planta de tratamiento de sus residuos líquidos. Además, en el año 2006 habría transado con Codelco Chile, por 115 millones, por el daño causado a sitios arqueológicos ubicados en la localidad de Taira, comuna de Calama, por una de sus empresas contratistas. El dinero sería destinado a la ejecución de un proyecto de conservación y difusión de las llamadas Momias Chinchorro, tarea que estaría a cargo del Departamento de Antropología de la Universidad de Tarapacá 57 .

Recientemente además se transó con Shell por la contaminación por hidrocarburos en la playa Las Petroleras de Antofagasta, en 120 millones de pesos, que se usarán para la

\footnotetext{
derecho procesal. También en el nuevo Código del Proceso en Uruguay, donde el artículo 220 del código (idéntico al artículo 184 del código modelo), evita que una demanda torpemente deducida o interpuesta en colusión con el responsable pudiere perjudicar el interés general comprometido, con el siguiente tenor: "Efectos de la cosa juzgada en procesos promovidos en representación de intereses difusos. La sentencia dictada en procesos promovidos en defensa de intereses difusos (art. 42) tendrá eficacia general, salvo si fuera absolutoria por ausencia de pruebas, en cuyo caso, otro legitimado podrá volver a plantear la cuestión en otro proceso”. Para todo, ver Véscovi, E., "La participación de la sociedad civil en el proceso. La defensa del interés colectivo y difuso. Las nuevas formas de legitimación”, en Revista Peruana de Derecho Procesal, N 4, 1997, p. 102, y Viera, L., "Las partes y el Código General del Proceso" [Primera parte] en Revista Uruguaya de Derecho Procesal, 1994, p. 41.

57 Según se relata en Noticia: "Consejo de Defensa del Estado y CODELCO firman acuerdo por daño ambiental”, en Diario La Nación (Chile), edición del 31 de enero 2006, disponible en página web: http://www. lanacion.cl/noticias/site/artic/20060131/pags/20060131170727.html (visitada al 22.01.2012).
} 
conservación de las momias Chinchorro y su postulación al patrimonio de la humanidad ${ }^{58}$, juicio en el que el CDE era tercero. En este mismo caso los particulares demandantes por la reparación del daño ambiental puro transaron con la compañía, cuando el juicio estaba en la Corte Suprema para los efectos de resolver un recurso de casación, logrando la reparación in natura solicitada, pero además, 600 millones de pesos a título de daño emergente, lucro cesante y daño moral (peticiones que no integraban la demanda), de los cuales renunciaron a 60 a favor del CDE, sin señalarse a qué título ${ }^{59}$.

Además, en el año 2009, el CDE firmó un acuerdo de avenimiento con Pretty Bright Shipping S.A. y Parakou Shipping Limited, empresas armadoras del buque Eider, con el que se puso término al juicio iniciado a raíz del derrame de 900 mil litros de petróleo en la bahía de Antofagasta, ocurrido en octubre de 2005. Lamentablemente el caso se ha visto envuelto en un escándalo a raíz de antecedentes que sugieren que los monitoreos ambientales que dieron por superada la emergencia por parte de la Armada de Chile, desarrollados por un perito privado y expertos de una universidad de la zona, serían falsos ${ }^{60}$.

Por otra parte, dado que no existe la obligación de requerir la aprobación del CDE, se desconocen otras transacciones entre privados e incluso es probable que el CDE no sepa del juicio como para intervenir oportunamente como tercero y, en consecuencia, no pueda al menos "monitorear" estos acuerdos.

Pese a la buena experiencia que el CDE dice tener en este tipo de transacciones, en que las sumas pagadas se destinan a fines ambientales ${ }^{61}$, esta situación cambiará, pues el proyecto de ley impone tajantemente que la acción ambiental "no podrá ser objeto de transacción o cualquier tipo de acuerdo que exima al autor de implementar medidas de reparación ambiental del daño causado" (art. 44).

\section{1. ¿QUiÉN DEBE RESPONDER DEL DAÑO AMBIENTAL?}

Para determinar entonces quién responde por el daño ambiental será fundamental determinar quién lo causa. En principio, de acuerdo a la LBGMA, responderá del daño ambiental quien lo cause con culpa o dolo.

Si quien realiza las obras u opera la vía es la empresa concesionaria y se causa un daño ambiental con ocasión de sus acciones o omisiones, en principio, en base al art. 35

${ }^{58}$ Según se relata en Noticia: "Shell repara daño ambiental y paga $\$ 600$ millones a pescadores", en Diario La Nación (Chile), edición del 16 de agosto 2010, disponible en página web: http://www.lanacion.cl/noticias/site/ artic/20100816/pags/20100816001411.html (visitada al 22.01.2012).

${ }^{59}$ Esta transacción, entre la compañía y los pescadores, está acompañada al expediente del caso, en Sentencia C. Apelaciones Antofagasta, 03.03.2008, "Sindicato de Pescadores de Artesanos con Shell Chile S.A.C.I. y otro", Rol $\mathrm{n}^{\circ}$ 340-2007 (v. nota ${ }^{\circ} 55$ ). No encontramos la que acordó con el CDE.

${ }^{60}$ En Comunicado de Prensa: "CDE firma acuerdo de avenimiento con empresa armadora de buque Eider", en Página Web Consejo de Defensa del Estado, Lunes 26 de enero 2009, disponible en dirección web: http://www. cde.cl (visitada al 12.01.2012).

${ }^{61}$ Según se relata en Noticia: "Shell repara daño ambiental y paga \$600 millones a pescadores", V. nota 55. 
de la Ley y 62 del Reglamento, ya revisados y pese a su relación con el Estado mediante una concesión, se señala que "responderá siempre la concesionaria" (y de "todo" daño), a menos que estos daños "sean exclusivamente imputables a medidas impuestas por el Ministerio de Obras Públicas, después de haber sido adjudicado el contrato".

Sin embargo, la solución no deja de tener aristas en las que vale la pena detenerse. Si se revisan la normativa y las bases de licitación de los proyectos ya adjudicados, se advierte que hay dos tipos de operatoria: una, en la que el Ministerio de Obras Públicas (MOP) licita, habiendo obtenido él la RCA (en base a sus estudios), la que obviamente traspasa más tarde a la concesionaria que se adjudica el contrato; y otra, en que el MOP licita, obligando a la concesionaria a ingresar el proyecto al SEIA, debiendo ella elaborar la DIA o EIA, tramitando el proyecto en el SEIA, figurando como titular etc., en base, en todo caso, a los estudios previos que le entrega el MOP y obligándose además a realizar una serie de exigencias ambientales adicionales a las que puedan resultar de la RCA, todas contenidas en las bases de licitación.

Con este panorama y no obstante el tenor del art. 35, es posible considerar que en caso de que el daño se haya causado por la concesionaria, pero habiendo seguido estrictamente las exigencias impuestas por el MOP (que le entregó los estudios ambientales referenciales o que obtuvo la RCA, etc.) o las impuestas por la autoridad (el SEA), ella alegue culpa exclusiva de un tercero, orden de autoridad o ejercicio legítimo de un derecho.

Si, en cambio, fue el daño ocasionado, por no seguir estas exigencias, no hay duda que responderá la concesionaria y lo hará, según la Ley 19.300, arts. 51 y siguientes, en base a su dolo o culpa, que resultará de fácil prueba.

\section{El ESTÁNDAR DE CONDUCTA EXIGIBLE A LAS CONCESIONARIAS RESPECTO A LOS DAÑOS AMBIENTALES.}

He dejado para el final el tema del criterio de imputación y los daños no previstos ${ }^{62}$, pues a nivel jurisprudencial ambos temas han sido abordados recientemente por la Corte Suprema, en un caso de daño ambiental y daños reflejos causados en relación al Embalse Pitama, por el actuar de una concesionaria y la sentencia es realmente esclarecedora.

Pues bien, el régimen de la LBGMA es subjetivo, pese a que el proyecto establecía responsabilidad civil extracontractual objetiva, como recomiendan los especialistas en materia ambiental y como de hecho establece la normativa en la UE (para las actividades del Anexo I y III) y varios de sus Estados para las actividades más riesgosas, o Portugal, Brasil, Argentina, Ecuador, etc., para todo daño al medio ambiente.

En todo caso, cuando el causante del daño es el propio Estado el tema es discutible. Bermúdez Soto se encarga de plantear el problema, conforme a dos posibilidades,

62 Para todo lo relativo a los daños previstos y no previstos en el SEIA, imprescindible consultar a Corral, H., "El sistema de impacto ambiental y la responsabilidad civil por daño al medio ambiente", en Revista de Derecho Administrativo Económico, P. Universidad Católica de Chile, vol. 1, N 1, enero-junio 1999, pp. 90-91. Se recomienda ver también a Hunter, I., "La culpa con la ley en la responsabilidad civil ambiental", en Revista de Derecho, Universidad Austral de Chile, Valdivia, vol. 18, N 2, diciembre 2005, pp. 9-25. 
pareciendo más cercano a la segunda: a) La opción natural, propia de la clase de daño a que se refiere, y considerando la expresión todo daño que fluye del sistema de responsabilidad de la LBGMA, conduce a entender que el régimen aplicable deba ser el de la Ley 19.300; y b) Que la administración del Estado respondería por los daños que ocasiona al medio ambiente de acuerdo con sus propias normas y no según las del derecho común, por consideración de la autarquía del derecho administrativo, la clase de relación jurídica involucrada, autonomía de aquel y por aplicación de los arts. 4, y 44 de la Ley 18.575, no procediendo entonces la acción ambiental, no por su irresponsabilidad en la materia, sino porque ella sería perseguible según las normas de su propio Derecho ${ }^{63}$.

Hernán Corral es de la opinión de que debería responder por falta de servicio cuando el daño ambiental no se haya previsto en la evaluación ambiental, cuando previéndose las medidas impuestas resultan erróneas e ineficientes o por falta de fiscalización, siempre que estos hechos hayan sido una de las causas directas y adecuadas del daño ${ }^{64}$.

Si bien el régimen es subjetivo, en el art. $52^{65}$ existe una presunción de culpa contra la legalidad que, siendo amplia, lamentablemente no consideró la infracción a las RCA, desconociendo la operatividad del sistema, pues justamente en este acto terminal del SEIA se impondrán al titular del proyecto una serie de exigencias en materias que no están normadas. Su infracción, en consecuencia, no cambiará el onus probandi.

Es importante advertir que por el tenor literal de la norma (que presume "la responsabilidad"), podría considerarse una presunción de causalidad ${ }^{66}$, aunque la mayoría de los fallos que se refieren al tema la estiman de culpabilidad ${ }^{67}$. Sin embargo, se ha resuelto que, al menos, por la relación entre el art. 52 y el art. 2329 del CC, dilucidar la relación de causalidad en la responsabilidad ambiental "trae aparejadas grandes dificultades, pudiendo incluso sostenerse que exista una atenuación en la exigencia de certeza plena respecto de este punto"68.

63 En Bermúdez, J., "La responsabilidad extracontractual de la Administración del Estado por falta de servicio y por el daño ambiental”, cit., pp. 251-255.

${ }^{64}$ Corral, H., "El sistema de impacto ambiental y la responsabilidad civil por daño al medio ambiente", cit., pp. 90-91.

${ }^{65}$ El Art. 52 de LBGMA establece: "Se presume legalmente la responsabilidad del autor del daño ambiental, si existe infracción a las normas de calidad ambiental, a las normas de emisiones, a los planes de prevención o de descontaminación, a las regulaciones especiales para los casos de emergencia ambiental o a las normas sobre protección, preservación o conservación ambientales, establecidas en la presente ley o en otras disposiciones legal o reglamentarias.

Con todo, sólo habrá lugar a la indemnización, en este evento, si se acreditare relación de causa a efecto entre la infracción y el daño producido".

${ }^{66}$ Incluso ya se habría fallado en este sentido: V. en Ropert, R.- Saavedra, R., "La protección del patrimonio cultural en la Ley 19.300 de bases generales de medio ambiente a la luz de dos sentencias recientes", cit., pp. 191-221.

${ }^{67}$ Entre otros, V. Sentencia C. Ap. Concepción, 15.09.2011, "Fisco de Chile con Servicio de Vertederos Los Maitenes", Rol 493-2011, cit. (n. 26).

${ }^{68}$ Parte del considerando 12 señala: "No escapa a estos sentenciadores que, en materia de vínculo causal, en casos sobre responsabilidad ambiental su dilucidación trae aparejado graves dificultades e, incluso, siguiendo a la doctrina más autorizada, podría sostenerse una atenuación en la exigencia de certeza plena respecto del punto. "Así, este tema crucial de la responsabilidad ambiental no está resuelto por la ley. El régimen general de responsabilidad civil permite recurrir a la norma del artículo 2329, que establece una presunción general 
Para la prueba y apreciación de la culpa en caso de daño ambiental causado con ocasión de la construcción y operación de una ruta concesionada -objeto de nuestro estudio- es fundamental revisar las obligaciones ambientales impuestas en la Ley de Concesiones, su reglamento, en las bases de licitación (dado el claro tenor del art. $1^{\circ}$ de la ley) y en el contrato; pero además las derivadas de la normativa ambiental y la respectiva resolución de calificación ambiental. Haremos hincapié en el estándar de conducta que se le exige en su actuar.

La RCA es el acto administrativo mediante el cual la autoridad ambiental califica en forma favorable (o no) los proyectos que han ingresado al SEIA, según si el titular declara bajo juramento en una Declaración de Impacto Ambiental o acredita que su proyecto cumplirá con la normativa ambiental vigente. En el caso que su proyecto genere los efectos, circunstancias o características del art. 11 de la LBGMA, deberá ingresar mediante un Estudio de Impacto Ambiental y, en consecuencia, junto con deber realizar una serie de estudios técnicos que justifiquen la evaluación de los impactos que según él producirá, se le exigirán medidas de mitigación, reparación o compensación apropiadas para los efectos que causará. Se trata, en muchos casos, de daños ambientales (afectaciones significativas) pero que estarán justificadas por nuestra legislación, ya que en sede administrativa se le exigirá mitigar, reparar o compensar.

De hecho, la definición de medida de reparación ${ }^{69}$ es absolutamente acorde a la definición de reparación (material) que da la ley para los efectos de la responsabilidad por daño ambiental. Y los ejemplos son bastante ilustrativos y útiles para los demandantes y jueces que enfrenten daños similares, como las medidas de "reparación" que se han exigido ante la afectación de flora del lugar (por ejemplo, reforestar todo lo cortado recuperando la cobertura vegetal dañada en condiciones similares o equivalentes a las existentes en forma previa) ${ }^{70}$, o la "compensación” exigida por ocupar irreversiblemente con la ruta parte del suelo de una reserva nacional (consistente en entregar en dominio

de responsabilidad por el hecho propio respecto de daños que, atendida su naturaleza, pueden ser atribuidos en principio a terceros. Esta inferencia puede entenderse efectuada implícitamente por la norma del artículo 52 de la Ley. (Se refiere a la Ley $N^{\circ} 19.300$ ). De este modo, a la manera de la ley alemana, cuando existen indicios claros y consistentes de que el daño se debió a la actividad de una cierta industria, se extiende el principio res ipsa loquitur, dejad que las cosas hablen por sí mismas, al terreno de la causalidad”. (Barros, E. Tratado de Responsabilidad Extracontractual, cit., pp. 807 y 808). Ver sentencia C. Ap. Copiapó, 5.3.2008, "Héctor Vallejo Choydeng con Compañia Minera San Esteban", Rol n 557-2006.

69 Respecto al Plan de Medidas de Reparación y/o Restauración, el Reglamento del SEIA establece que ellas "tienen por finalidad reponer uno o más de los componentes o elementos del medio ambiente a una calidad similar a la que tenían con anterioridad al daño causado o, en caso de no ser ello posible, restablecer sus propiedades básicas”. (art. 59).

${ }^{70}$ Por ejemplo, el proyecto Concesión Internacional Ruta 5 Tramo Los Vilos-La Serena, ingresó al SEIA, mediante un EIA, por afectar significativamente ciertos recursos naturales (al limpiar la faja, se perderá suelo agrícola; se afectarán los suelos en que se acopien materiales; puede afectar especies de flora nativas y perturbará el hábitat de la fauna.). Se comprometió entonces a no usar suelos agrícolas de clase I, II y III, acopiar sólo en suelos de clase V a VIII, recuperándolos al finalizar la etapa de construcción. Respecto a la flora, se compromete a reforestar todo lo cortado recuperando la cobertura vegetal dañada en condiciones similares o equivalentes a las existentes en forma previa. Respecto a la fauna, se establece un programa de seguimiento y monitoreo, con medidas en caso de afectación. En RCA N 38/1998, de fecha 14.05.1998, COREMA, Región de Coquimbo. 
el equivalente a la superficie efectivamente afectada en un sector aledaño a la reserva, equivalente en valor natural al sector a expropiar) ${ }^{71}$ o construir un centro de información a los visitantes, de 50 metros cuadrados, por la reubicación de una zona de picnic y la afectación al paisaje $\mathrm{e}^{72}$.

Por ello, es fundamental revisar, en el caso concreto, qué impactos o efectos mayores indicó el titular y qué medidas consideró apropiadas especialmente para repararlo o compensarlo. Si no implementó dichas medidas o no lo hizo adecuadamente y ello es la causa del daño, existirá culpa sin duda. También la habrá si ni siquiera los previó en la evaluación ambiental pues él, como titular, es quien conoce su proyecto, la tecnología que usará, los efectos que se han dado en otras latitudes, y quien está obligado a identificar los impactos que causará y hacerse cargo de ellos, en base al principio "quien contamina paga”. Si el daño era imprevisible para todos, podría pensarse en eximirlo de responsabilidad, pero no cuando era previsible para aquellos que manejan o deben manejar información técnica actualizada y completa al respecto.

Pues bien, la Ley de Concesiones señala en su art. $1^{\circ}$ que "la ejecución, reparación, conservación o explotación de obras públicas fiscales, por el sistema establecido en el artículo 87 del decreto supremo $\mathrm{N}^{\circ}$ 294, del Ministerio de Obras Públicas, de 1985, las licitaciones y concesiones que deban otorgarse ...se regirán por las normas establecidas en el presente decreto con fuerza de ley, su reglamento y las bases de la licitación de cada contrato en particular, que el Ministerio de Obras Públicas elabore al efecto". El Reglamento precisa que el concesionario deberá dar "cumplimiento cabal, íntegro y oportuno" del contrato de concesión; ejecutar en forma "correcta" proyectos y obras, y cumplir "todas" las obligaciones establecidas en el contrato de concesión, sin perjuicio de las funciones de dirección y control que corresponden al Ministerio de Obras Públicas (art. 63).

La ley le exige responder de "los daños, de cualquier naturaleza", que con motivo de la ejecución de la obra o de la explotación de la misma se ocasionaren a terceros, a menos que sean exclusivamente imputables a medidas impuestas por el MOP, después de haber sido adjudicado el contrato (art. 35); y el art. 62 del Reglamento agrega que responderá, de igual forma, de los daños al medio ambiente. Para prevenir estos daños, el reglamento exige perentoriamente que el concesionario deberá adoptar, durante la concesión, "todas las medidas para evitar" daños a terceros y al personal que trabaja en la obra, como "todas las precauciones" para evitar daños a la propiedad de terceros y al

${ }^{71}$ Según la RCA N 166/2001, de 19.03.2001, COREMA, Región de Valparaíso, en el proyecto "Mejoramiento de la ruta 68 entre los kms 85 a 95", el titular reconoce que el enlace se emplazará en la Reserva Nacional Lago Peñuelas y se le exige compensar el equivalente a la superficie efectivamente afectada en un sector aledaño a la reserva, equivalente en valor natural al sector a expropiar.

72 Según RCA N 467/2000 de 06.09.2000, COREMA Región de Valparaíso, en el Proyecto “Autopista Troncal Sur”, que bordea el Jardín Botánico Nacional, se consideraron medidas de mitigación para la etapa de construcción (como presentar un estudio de paisajismo y revegetación de taludes, que incluya consideraciones estéticas, biológicas y de mecánica de suelos, especies, disposición y plan de mantención; y reubicar la zona de picnic) y para la etapa de operación, la medida de compensación de construir un centro de información a los visitantes, de 50 metros cuadrados. 
medio ambiente durante la concesión de la obra (art. 62). Y para ello se establecen una serie de obligaciones complementarias ${ }^{73}$.

Por otra parte, en las últimas bases de licitación se detallan más de 100 medidas tipo de mitigación y control de los impactos ambientales (en las aguas, suelo, fauna, flora, patrimonio arqueológico, etc.) y se reitera siempre que debe cumplir todo aquello que adicionalmente imponga la RCA del proyecto.

Pero antes de revisar las obligaciones que una RCA puede imponer, es importante advertir que en la legislación ambiental se exige al titular del proyecto o actividad, durante la fase de construcción y ejecución del mismo, someterse "estrictamente" al contenido de la RCA respectiva (nuevo inc. final del art. 24 LBGMA) y al "permanente cumplimiento" de las normas y condiciones sobre la base de las cuales se han aprobado o aceptado los Estudios y DIAs, de las medidas e instrumentos que establezcan los Planes de Prevención y de Descontaminación, de las normas de calidad y emisión, así como de los planes de manejo establecidos en la LBGMA (art. 64).

Pues bien, de toda RCA debería poder extractarse entonces un listado de las obligaciones del titular del proyecto o actividad, entre las cuales destacan: las que permitan cumplir los aspectos normados en Chile (tales normas de emisión y calidad, Planes de Prevención y Descontaminación, y normativa sectorial propiamente tal: en materia de aguas, recursos naturales, riles, etc.; todas ellas resumidas en el ICE de cada proyecto, debiendo el titular señalar la normativa que se le aplica y cómo la cumple); las que permitan asegurar que, en un aspecto no normado en Chile, el impacto ha sido mitigado; las que asume como compromisos voluntarios; y, en el caso de un EIA, especialmente, las que permitan asegurar que, produciéndose un efecto, característica o circunstancia del art. 11, estos han sido mitigados, o reparados o compensados apropiadamente y las que derivan de su Plan de Seguimiento.

73 Con una clara finalidad de identificar los impactos y prevenir daños, en la oferta deberán estar las consideraciones ambientales y ecológicas del proyecto y el cómo se cumple con lo establecido en los planes regionales de desarrollo urbano, los planes reguladores comunales, intercomunales y metropolitanos (art. 7 de la Ley de Concesiones). Además, antes de la entrada en servicio de la obra, deberá constituir una garantía de explotación "suficiente", de naturaleza y monto establecidos en las Bases de Licitación (arts. 13 y 14), precisando el Reglamento que las bases podrán solicitar garantías de construcción y de explotación de la obra (art. 17 letra e), que regula respectivamente en los arts. 34 y 35. Hipotéticamente al menos, existe también la posibilidad de que las bases exijan un seguro de responsabilidad civil por daño ambiental.

Además, mientras dure el contrato, debe el concesionario entregar al MOP (para que verifique la buena marcha de ella y el debido cumplimiento de sus obligaciones) información exacta y fidedigna de su gestión empresarial (art. 30 bis) y efectuar auditorías, cuando se lo requiera el MOP por resolución fundada, para comprobar la veracidad y exactitud de las informaciones que se le hayan proporcionado (art. 30 bis). El Reglamento agrega que debe otorgar libre acceso al inspector fiscal a los antecedentes que sean necesarios para su labor de fiscalización y control del cumplimiento de las obligaciones emanadas del contrato de concesión (art. $43 \mathrm{n}^{\circ}$ 1); y, debe, adicionalmente, mantener un Reglamento Interno con todas las normas aplicables a la concesión, con especial mención a las medidas de mantenimiento y protección de las áreas revegetadas y realizar los controles, mediciones y estadísticas que las bases de licitación le exijan, respondiendo de la veracidad de la información (art. 59). 
Finalmente, si bien es cierto que la LBGMA construyó el SEIA bajo el supuesto de que es el titular quien conoce el proyecto y quien debe indicar qué impactos causará o "puede causar", no lo es menos que es factible que las variables no se comporten como se esperaba y que, por ejemplo, se genere un impacto o daño no previsto, no evaluado y que, en consecuencia, no considera una medida para ser neutralizado, minimizado, reparado, compensado, etc. Así lo reconoce el nuevo art. 25 quinquies inc. $1^{\circ}$ ) para los EIA, cuando señala que si las variables evaluadas y contempladas en el plan de seguimiento sobre las cuales fueron establecidas las condiciones o medidas hayan variado sustantivamente en relación a lo proyectado o no se hayan verificado, el titular, además de poder solicitar la revisión del plan de seguimiento, tendrá la obligación -se infiere claramente de la norma- de "adoptar las medidas necesarias para corregir dichas situaciones”. Por ello, es frecuente encontrar en las RCA la exigencia al titular del proyecto evaluado de informar oportunamente a la autoridad la ocurrencia de los impactos no previstos, "asumiendo acto seguido las acciones necesarias para mitigarlos, repararlos y/o compensarlos, según corresponda”.

Como vemos, el nivel de conducta exigido al concesionario, sea para prevenir, corregir, reaccionar en materia ambiental, etc., es altamente exigente: debe tomar "todas" las medidas para prevenir daños a terceros y al medio ambiente y debe no sólo mitigar, compensar o reparar los daños ambientales previstos en la evaluación ambiental, y hacerlo apropiadamente, sino también aquellos "no previstos" 74 , siempre que no exista un caso fortuito o fuerza mayor.

Lo anterior fue abordado recientemente por la Corte Suprema y la doctrina ${ }^{75}$, con ocasión del caso Pitama, donde la Asociación de canalistas del embalse ejerció conjuntamente la acción ambiental y las acciones indemnizatorias ordinarias. Desechada la demanda en primera y segunda instancia, la Excma. C.S. acogió la casación en el fondo interpuesta por los canalistas y procedió a invalidar de oficio el fallo por adolecer de un vicio de casación en la forma, dictando la respectiva sentencia de reemplazo, dando lugar a las peticiones (Rol 396/2009 de fecha 20 de abril de 2011). Los hechos acreditados pueden sintetizarse en que la concesionaria se adjudicó un proyecto de mejoramiento de la Ruta 68, exigiéndole tanto la normativa como las bases de licitación y su RCA, que debía disponer del material sobrante en un botadero determinado, evitando toda contaminación, inundación o alteración de las aguas del lugar, mediante obras de drenaje y otras medidas. Dado que las medidas implementadas no fueron suficientes y que incluso la concesionaria vulneró varias normas de protección, se originó erosión en los taludes del botadero y por el escurrimiento de las aguas, se arrastró el material al embalse, contaminando sus aguas y fondo; e impidiendo además que puedan regar los

${ }^{74}$ Lo anterior no es compartido absolutamente por todos o no lo es sino en ciertas circunstancias. Ver Corral, H., "El sistema de impacto ambiental y la responsabilidad civil por daño al medio ambiente", cit., p. 87; y Barros, E. Tratado de responsabilidad extracontractual, cit., p. 802.

${ }^{75}$ Sentencia C.S., 20.04.2011, “Asoc. Canalistas Embalse Pitama con Soc. Concesionaria Rutas del Pacífico S. A.”, Rol n 396-2009, comentado por Boettiger, Camila, "Embalse Pitama: jurisprudencia de daño ambiental”, en Revista Actualidad Jurídica, Universidad del Desarrollo, N²4, julio 2011, p. 420. 
predios como antes (pues los sistemas para extraer agua exigen que no haya sedimentos). Incluso fracasó un proyecto turístico ya aprobado por la CORFO. Se ordenó, en definitiva, la reparación material del embalse y las indemnizaciones a los personalmente afectados, reservándose su especie y monto para la etapa de ejecución de la sentencia o en un procedimiento diverso (art. 173 del CPC).

En su sentencia, la Corte Suprema fijó importantes pautas. En primer lugar, a diferencia de lo establecido en las sentencias anteriores del juicio (en que se estimaron cumplidas las obligaciones de la concesionaria y prácticamente se consideraron como causas del daño las bases de licitación del MOP $)^{76}$, la Corte Suprema consideró varias obligaciones reglamentarias incumplidas, operando la presunción contra la legalidad del art. 52 LBGMA. Para ello se revisaron detenidamente sus obligaciones derivadas de las exigencias de la ley de concesiones, bases de licitación, reglamentos, RCA e inclusive del Manual de Carreteras.

La Corte señaló en los considerandos 28 y 29 que, además de estos incumplimientos, la concesionaria actuó con culpa pues las medidas adoptadas fueron ineficientes y "la demandada debió prever el daño que esta situación produciría, y que efectivamente se produjo producto de la falta de medidas de su parte en la ejecución de los trabajos y mantención y cierre del botadero”. O sea, no sólo está obligada a lo que le exige la normativa o lo que se previó en la RCA de la evaluación ambiental de su proyecto realizada en base a la información que él entrega, sino además, su obligación "era llevar a cabo todas las acciones que permitieran mitigar y reparar adecuadamente el impacto ambiental negativo de su actividad, única forma de entender un desarrollo sustentable, que es al que tiende el legislador".

Por otra parte, se señaló que "el cumplimiento formal de las leyes, reglamentos y compromisos particulares no es suficiente para exculparse de los daños ocasionados”, pues "la observancia de ellos no dispensa tampoco del deber de conformarse a la obligación general de previsión. El que se ha amoldado a los reglamentos también será responsable si causa un perjuicio que pudo y debió prever", citando a Ripert y Planiol (considerando 28) ${ }^{77}$.

Incluso se precisa que "...su obligación es llevar a cabo un adecuado desarrollo ambiental de su proyecto que permita evitar todo daño que su actividad causa al medio ambiente. En efecto, el elemento subjetivo de la culpa se satisface por el conocimiento de la acción que se desarrollará y los riesgos anormales que enfrentará la persona que la realice, cobrando importancia las especiales capacidades y conocimientos técnicos y fácticos del sujeto actuante, de modo que en este caso, la culpa se ha apreciado de acuerdo a las circunstancias y condiciones objetivas de las partes, conforme a las cuales les era exigible una conducta determinada, en este evento el deber de previsión y diligencia que es posible esperar de ellas, especialmente a las personas que actuaron por la demandada, puesto que para que

\footnotetext{
${ }^{76}$ Ver considerando tercero del fallo recién citado. Señala sobre el fallo de primera instancia que revoca: "Razona luego sobre la imputabilidad del daño causado, para encontrar su origen no en el actuar de la sociedad demandada, sino en las Bases de Licitación del Proyecto de que se trata y en las especificaciones técnicas del propio contrato".

${ }^{77}$ Lo cursivo es nuestro.
} 
exista responsabilidad, enseñan Marcel Planiol y Jorge Ripert, no es necesario que se haya previsto efectivamente el daño preciso que se produjo, sino que basta con que se haya debido prever que iba a resultar un perjuicio del acto o de la omisión" (considerando 28).

En fin, la concesionaria debe responder por un daño que no se previó en la evaluación ambiental, pero debe hacerlo pues durante ella sí se previó un impacto menor relacionado, cuyas medidas de neutralización no fueron suficientes y no se tomaron otras, pese a tener la capacidad y conocimiento para prever las consecuencias mayores posteriores.

Pues bien, no podemos sino concordar con lo recién expuesto pues sólo con este alto nivel de exigencias, propio de las actividades que implican altos riesgos (y que justifican la adopción de la responsabilidad objetiva como criterio de imputación en la Unión Europea y tantos otros países), podremos realmente satisfacer el principio de la responsabilidad y el de que quien contamina paga; contribuir quizás a la tarea de prevenir la ocurrencia de daños ambientales y, junto a ello, impedir que la sociedad siga asumiendo costos ambientales de unos pocos.

Esperamos además que el fallo incentive a realizar una mejor evaluación ambiental, lo que es particularmente importante en el área de las concesiones, donde se ha podido advertir -aunque ésta no sea la sede para entrar en detalle- que la política del MOP está bastante alejada de la temática ambiental, lo que queda en evidencia en que por años no ingresó varios de sus proyectos de autopistas al SEIA (bajo el pretexto de que eran autovías) o las ingresaba mediante simples declaraciones juradas debiendo hacerlo por estudios de impacto ambiental (y en consecuencia se exoneraba de la participación ciudadana obligatoria y, obviamente, de mitigar, reparar o compensar sus efectos negativos) o licitaba sin la evaluación ambiental terminada ${ }^{78}$; incluso más, pese a todos los conflictos ambientales que ha enfrentado, sigue presentando proyectos de mala calidad, que se traducen en largas evaluaciones ambientales e incluso en rechazos por falta de información considerada básica o esencial, como los permisos o autorizaciones ambientales sectoriales que debe obtener ${ }^{79}$. De hecho, el capítulo ambiental del Manual de

${ }^{78}$ Bitrán, E. y Villena, M., "El nuevo desafío de las concesiones de obras públicas en Chile. Hacia una mayor eficiencia institucional", en Estudios Públicos, Centro de Estudios Públicos, N 117 (verano 2010), pág. 202. Además, ver la Noticia: "Piden antecedentes por falta de estudios de impacto ambiental en la construcción de las autovías concesionadas”, Portal virtual del Senado de la República de Chile, 13 de septiembre de 2005. Disponible en: http://www.senado.cl/prontus_galeria_noticias/site/artic/20080128/pags/20080128113154. html [Fecha consulta: 8 de marzo de 2012], y Noticia: "Exigen evaluación de impacto ambiental de la ruta $\mathrm{CH}$ 60 en la V Región”, Portal virtual del Senado de la República de Chile, 4 de octubre de 2006, disponible en página web: http://www.senado.cl/prontus_galeria_noticias/site/artic/20080129/pags/20080129154945.html [Fecha consulta: 8 de marzo de 2012].

${ }^{79}$ Por ejemplo, en el proyecto "Reposición Ruta A-557, Sector Quetraine-Cariquima-Escapiña, I Región de Tarapacá”, se omitió Plan de rescate y traslado de fauna, el Plan de replante de especies vegetales a intervenir, el Plan de contingencias de derrames que pueden afectar los bofedales aledaños al lugar del proyecto, el cual le importó solicitar el permiso ambiental sectorial del art. 106 del Reglamento del SEIA, que no identifica como aplicable a su proyecto. También tenemos que en el proyecto "Reposición/Construcción Puente Lepe Uno Comuna Curacaví, Provincia Melipilla, Región Metropolitana” el titular no indicó en su primera presentación la localización de faenas, empréstitos y botaderos de estériles, dejándose a consideración del contratista dicha decisión; no presentó Plan de Manejo Ambiental para obras anexas ni Plan de Contigencias ante accidentes. 
Carreteras, de diciembre de 2010, con el cual se elaboran los estudios referenciales del MOP y se redactan las bases de licitación, está atrasadísimo, no sólo porque no considera la reforma a la institucionalidad ambiental de la Ley 20.417 de enero del mismo año 2010, sino que no considera cambios técnicos importantes que ha habido, como la consideración de los efectos sinérgicos o acumulativos, y nuevas normas en materia de bosque nativo, aire, residuos etc.

\section{BIBLIOGRAFÍA}

Amunátegui, A., "Responsabilidad civil ambiental y seguro", en Revista de Derecho de la Empresa, Universidad Adolfo Ibáñez-Legis, N 6, 2006, pp. 25-40.

ANDORno, L., "Aspectos constitucionales de la protección al medio ambiente", en Jurisprudencia Ambiental (Arg.), IV, 1998, 930 ss.

BANFi, C., "De la responsabilidad civil como instrumento de protección ambiental", en Revista Chilena de Derecho Privado, Fundación Fernando Fueyo L.-Universidad Diego Portales, $\mathrm{N}^{\circ} 2$, 2004, pp. 19-70.

Benjamin, A., A responsabilidade civil pelo dano ambiental no direito brasileiro e as licôes do direito comparado, en Revista Roma e America, Diritto romano comune, Universidad de Roma-Tor Vergata, $\mathrm{N}^{\circ}$ 6, 1998, pp. 129-147.

Bermúdez, J., "La responsabilidad extracontractual de la administración del Estado por falta de servicio y por el daño ambiental”, en Revista de Derecho, P. Universidad Católica de Valparaíso, XXIII (Valparaíso, Chile, 2002), 245-256.

Barros, E., Tratado de responsabilidad extracontractual, 1a edición, Editorial Jurídica de Chile, Santiago, 2006, $1230 \mathrm{p}$.

Bitrán, E. y Villena, M., "El nuevo desafío de las concesiones de obras públicas en Chile. Hacia una mayor eficiencia institucional", en Estudios Públicos, Centro de Estudios Públicos, $\mathrm{N}^{\circ} 117$ (verano 2010), pp. 175-217.

Bordalí, A., Tutela jurisdiccional del medio ambiente, Editorial Fallos del Mes, Santiago, 2004, 485 p.

Brahm, A., "Autopistas urbanas", en Revista ARQ-Ensayos y Documentos, Nº 60, junio 2005, pp. 28-39.

BuSNELli, F., Illecito civile (estratto dall'aggiornamento I della Enciclopedia Giuridica 1991), Istituto della Enciclopedia Italiana, Roma, 1991.

Camps, C., Particularidades del proceso civil por daño ambiental, en Jurisprudencia Ambiental, IV, 1998, Nº 6120 (número especial), pp. 31-41.

Corral, H., "Daño ambiental y responsabilidad civil del empresario en la ley de bases del medio ambiente”, en Revista Chilena de Derecho, P. Universidad Católica de Chile, vol. $23 \mathrm{~N}^{\circ} 1$, 1996, pp. 143-177.

Corral, H., "El sistema de impacto ambiental y la responsabilidad civil por daño al medio ambiente", en Revista de Derecho Administrativo Económico, P. Universidad Católica de Chile, vol. 1, $\mathrm{N}^{\circ}$ 1, enero-junio 1999, pp. 79-93.

Tampoco informó oportunamente cómo iba a intervenir formación xerófita protegida por la Ley $N^{\circ} 20.283$ sobre recuperación del bosque nativo y fomento forestal, no señala el peso máximo de los camiones que operarán en la faena en conformidad al DS N $N^{\circ}$ 158/80 del MOP, no solicita el permiso ambiental sectorial del art. 102 del Reglamento del SEIA referido a corta o explotación de bosque nativo en cualquier tipo de terrenos a que se refiere el Art. $21^{\circ}$ del DL $701 / 74$ sobre Fomento Forestal, etc. 
De la BARra, F., "Responsabilidad extracontractual por daño ambiental: el problema de la legitimación activa”, en Revista Chilena de Derecho, P. Universidad Católica de Chile, vol. 29 $\mathrm{N}^{\circ} 2$, 2002, pp. 367-415.

Declaración de Rio sobre el Medio Ambiente y Desarrollo, Naciones Unidas, 1992, disponible en: http://www.un.org/esa/dsd/agenda21_spanish/res_riodecl.shtml.

Diez J. L., El daño extracontractual. Jurisprudencia y doctrina, Editorial Jurídica de Chile, 1a Edición, Santiago, 1997, 291 p.

Fernández P., "Responsabilidad y acción ambiental”, en Ius Publicum, Universidad Santo Tomás, $\mathrm{N}^{\circ} 10,2003$, pp. 89-96.

Figueroa E.-Asenjo R.-Valdés, S.-Praus, S., "La responsabilidad civil ambiental, el daño al medio ambiente y su valor: una aproximación legal y económica”, en Revista de Derecho Ambiental, Centro de Derecho Ambiental, Universidad de Chile, N², 2006, pp. 69-95.

Greene, M. y Mora, R., "Las autopistas urbanas concesionadas. Una nueva forma de segregación”, en Revista ARQ-Ensayos y Documentos, N 60, junio 2005, pp. 56-58.

GuZMán, R., La regulación constitucional del ambiente en Chile. Aspectos sustantivos y adjetivos, historia, doctrina y jurisprudencia, $2^{a}$ edición, Abeledo Perrot, Santiago, 2010, 357 p.

Hunter, I., "La culpa con la ley en la responsabilidad civil ambiental", en Revista de Derecho, Universidad Austral de Chile, Valdivia, vol. 18, N² 2, diciembre 2005, pp. 9-25.

PoKlepovic, I., "Aspectos vinculados a la protección del patrimonio cultural a través del ejercicio de la acción ambiental de la Ley n ${ }^{\circ} 19.300$ sobre bases del medio ambiente", en Revista de Derecho, Consejo de Defensa del Estado, Vol. 16, N 16, diciembre 2006, pp. 185-198.

RAmírez., J. A., "La contaminación y daño al suelo y subsuelo en la legislación chilena y comparada", en Revista de Derecho, Consejo de Defensa del Estado, vol. 1, N 1, 2000.

Roperts, R. y SAAVEdra, R., "La protección del patrimonio cultural en la Ley 19.300 de bases generales de medio ambiente a la luz de dos sentencias recientes", en Revista de Derecho, Consejo de Defensa del Estado, vol. 11, N 11, junio 2004, pp. 191-221.

Uriarte, A., "Jurisprudencia ambiental”, en Revista de Derecho, Consejo de Defensa del Estado, vol. 16, N 16, diciembre 2006, pp. 99-146.

Valenzuela, R., "Responsabilidad civil por daño ambiental en la legislación chilena”, en Roma e America, Diritto romano comune, Universidad de Roma-Tor Vergata, $N^{\circ} 11,2001$, pp. 3-19.

Valenzuela, R. Derecho ambiental: presente y pasado, Edit. Jurídica de Chile, Santiago, 2010, 448 p.

VÉsCovi, E., "La participación de la sociedad civil en el proceso. La defensa del interés colectivo y difuso. Las nuevas formas de legitimación”, en Revista Peruana de Derecho Procesal, 1997.

Viera, L., Las partes y el Código General del Proceso [Primera parte] en Revista Uruguaya de Derecho Procesal, 1994, p. 35-41.

VIDAL, A., "Las acciones civiles derivadas del daño ambiental en la Ley N ${ }^{\circ} 19.300 "$, en Revista de Derecho, P. Universidad Católica de Valparaíso, XXXIX (2do sem.) 2007, pp. 119-140. 